\title{
Instability of imperfect composite cylindrical shells under combined loading
}

DOI:

10.1016/j.compstruct.2006.02.031

\section{Document Version}

Accepted author manuscript

Link to publication record in Manchester Research Explorer

\section{Citation for published version (APA):}

Tafreshi, A., \& Bailey, C. G. (2007). Instability of imperfect composite cylindrical shells under combined loading. Composite Structures, 80(1), 49-64. https://doi.org/10.1016/j.compstruct.2006.02.031

\section{Published in:}

Composite Structures

\section{Citing this paper}

Please note that where the full-text provided on Manchester Research Explorer is the Author Accepted Manuscript or Proof version this may differ from the final Published version. If citing, it is advised that you check and use the publisher's definitive version.

\section{General rights}

Copyright and moral rights for the publications made accessible in the Research Explorer are retained by the authors and/or other copyright owners and it is a condition of accessing publications that users recognise and abide by the legal requirements associated with these rights.

\section{Takedown policy}

If you believe that this document breaches copyright please refer to the University of Manchester's Takedown Procedures [http://man.ac.uk/04Y6Bo] or contact uml.scholarlycommunications@manchester.ac.uk providing relevant details, so we can investigate your claim.

\section{OPEN ACCESS}


Tafreshi, A. \& Bailey, Colin G., Sep. 2007 In : Composite Structures. 80, 1, p. 49-64 16 p.

\title{
INSTABILITY OF IMPERFECT COMPOSITE CYLINDRICAL SHELLS UNDER COMBINED LOADING
}

\author{
Azam Tafreshi* and Colin G Bailey \\ School of Mechanical, Aerospace and Civil Engineering, MACE \\ The University of Manchester, P.O.Box 88, Sackville Street \\ Manchester M60 1QD, United Kingdom \\ *Corresponding author (azam.tafreshi@manchester.ac.uk)
}

\begin{abstract}
A numerical study using the non-linear finite element analysis has been carried out to investigate the response of composite cylindrical shells subject to combined loading. The interaction buckling curves of perfect composite cylinders subject to different combinations of axial compression, torsion, bending and lateral pressure are obtained. The postbuckling analysis of composite cylinders with geometric imperfections of eigenmode-shape is carried out to study the effect of imperfection amplitude on the critical buckling load. The initial buckling load of composite shells is substantially reduced by the existence of imperfections. Here it is shown that the effects of imperfections are more apparent when the composite cylindrical shells are subject to combined loadings. The results show that the buckling and non-linear response of geometrically imperfect shell structures subjected to complex loading conditions may not be characterized correctly by an elastic linear bifurcation buckling analysis.
\end{abstract}

Keywords: Composites, finite element method, buckling and postbuckling, laminated cylindrical shells, external pressure, axial compression, torsion, bending, combined loading

\section{NOMENCLATURE}

$\mathrm{E}_{11}, \mathrm{E}_{22}, \mathrm{G}_{12}, v_{12} \quad$ material constants

$\mathrm{L}, \mathrm{r}, \mathrm{t} \quad$ mength, radius and thickness of the overall cylindrical shell, respectively

M bending moment 


$\begin{array}{ll}\mathrm{M}_{\mathrm{c}} & \text { critical bending moment of a perfect cylinder under bending } \\ & \text { alone } \\ \mathrm{P} & \text { pressure } \\ \mathrm{P}_{\mathrm{c}} & \text { critical buckling pressure of a perfect cylinder under external } \\ & \text { pressure alone } \\ \mathrm{R} & \text { compressive axial load } \\ \mathrm{R}_{\mathrm{c}} & \text { critical buckling load of a perfect cylinder under axial } \\ & \text { compression alone } \\ \mathrm{T} & \text { torque } \\ \mathrm{T}_{\mathrm{c}} & \text { critical buckling load of a perfect cylinder under torsion } \\ & \text { alone } \\ \mathrm{U}\left(\text { or } \mathrm{u}_{\mathrm{x}}\right), \mathrm{v}\left(\text { or } \mathrm{u}_{\mathrm{y}}\right), \mathrm{w}\left(\text { or } \mathrm{u}_{\mathrm{z}}\right) & \text { axial, circumferential and radial displacements, respectively } \\ \mathrm{x}, \mathrm{y}, \mathrm{z} & \text { axial, circumferential and radial coordinates, respectively } \\ \psi_{\mathrm{x}}, \psi_{\mathrm{y}}, \psi_{\mathrm{z}} & \text { rotation about the } \mathrm{y}, \mathrm{x}, \text { and } \mathrm{z} \text { axes, respectively }\end{array}$

\section{INTRODUCTION}

Laminated composite materials are increasingly being used in the aerospace, civil, marine, automobile, and other engineering industries. This is due to their high strength and stiffness-to-weight ratios. The phenomenon of progressive failure in laminated composite structures is yet to be understood, and as a result, reliable strategies for designing optimal composite structures for desired life and strength are in demand [1-3].

In previous studies carried out by the first author [4-6], the effects of delamination on the buckling and postbuckling behaviour of composite cylindrical shells subject to axial compression and lateral pressure were investigated. The loads were either applied individually [1-2] or were combined [3]. Despite the relatively widespread attention given to the problem of delamination in laminated composites, there is hardly any information available on the effect of delamination in a composite cylindrical shell under combined loading. However, this study could not be performed without deep insight into the behaviour of a typical intact composite cylinder, with or without geometric imperfections, subject to complex loading conditions. 
Thin-walled circular cylindrical shells are very often loaded in a way that the three buckling membrane forces; axial compression, circumferential compression and shear, are not applied individually but in combination. Therefore, a designer not only has to consider the buckling characteristics of a cylindrical shell under fundamental stress states, but also the interactive buckling.

There is a reasonable amount of work on the instability response of laminated cylindrical shells under axial compression, pressure, external pressure, bending and torsion [7-17] applied individually. Ref. [18] consists of a comprehensive study on the stability of cylindrical steel shells under combined loading. Thus, very limited information on the instability response of composite shells under combined loading is available [19-30] and most of it does not consider the postbuckling response which, if considered, will result in significant cost savings. Most of the published data deals with the buckling response of compression-loaded composite shells. The early work of Manuel Stein [31] on the effects of geometrical imperfections on the stability of isotropic plates and shells must also be cited.

The traditional method for designing thin-walled shell structures to resist buckling failure is to predict the buckling load of the shell using the analytical or numerical methods. This buckling load will then be reduced with an empirical reduction factor accounting for the imperfections of the structure. The other most realistic, but costly, approach is to analyse the actual imperfect shell structure as generated from measurements after fabrication and erection[11,12, 18, 28, 29, 32-34]. This imperfection data can be directly implemented into Finite Element (FE) models and then analysed. The other most recent and feasible approach is to introduce a simple equivalent geometric imperfection which properly simulates the physical characteristics of the shell structure subject to buckling. This equivalent geometric imperfection can be either of the eigenmode shape $[23,26]$ or can be defined analytically $[16,21,27]$. However, the amplitude of the imperfection shape has a great influence on the non-linear response of the shell structure. Therefore, imperfection 
amplitude usually has to be calibrated against existing experimental databases for known shell buckling cases.

This paper deals with the buckling and postbuckling analysis of perfect and imperfect composite cylindrical shells subject to combined loading. The loading cases considered are axial compression, lateral pressure, torsion and bending, either applied individually and in combination. At most, the combination of three different types of loadings are considered. First, the interactive buckling curves of a typical cylindrical shell subject to different combinations of the preceding mentioned load cases are obtained. Whenever possible, the results are compared with corresponding numerical or analytical studies presented by other authors. The postbuckling response of composite cylinders with geometric imperfections of eigenmode-shape is carried out to study the effect of imperfection amplitude on the critical buckling load, when the loads are applied either individually or in combination. The analysis has been carried out using ABAQUS 6.4 [35], which is available on the mainframe computer, Bezier, at the Manchester Computing Centre.

\section{BUCKLING AND POSTBUCKLING ANALYSIS USING THE FINITE ELEMENT METHOD}

Fig. 1 shows a typical cylindrical shell subjected to simultaneous loading of axial compression, $\mathrm{R}$, torque, $\mathrm{T}$, bending moment, $\mathrm{M}$, and lateral pressure, $\mathrm{P}$. Throughout this study the external pressure is assumed to be positive and the internal pressure is assumed to be negative. Fig. 1a shows a differential element of a perfect cylindrical shell segment with the coordinate axes. The axial coordinate is $\mathrm{x}$, the circumferential coordinate is $\mathrm{y}$, and the thickness coordinate normal to the shell surface is $\mathrm{z}$. The circumferential coordinate can be replaced by $\mathrm{y}=\mathrm{r} \beta$. The axial $\operatorname{load}(\mathrm{R})$ is a uniform compressive force applied at the ends of the shell. The internal or external pressure is also uniformly distributed on the inner or outer surface of the shell, respectively. To apply pure bending or torsional moments, using the coupling technique in ABAQUS, all the nodes on each end cross-section were kept on the same respective plane. Then two concentrated loads in opposite directions were applied in the $\mathrm{x}$ direction or $\mathrm{z}$ direction to simulate bending or 
torsion, respectively. See Figs.1c and 1e. This method of loading will ensure that the shell is subject to pure bending or torsion and the end cross-sections remain on the same planes after deformation, which properly models the actual experimental conditions. Also, the two concentrated loads applied would not create a very high local stress concentration.

For the finite element analysis of a typical cylindrical shell, a single layer of shell elements, designated S8R in ABAQUS, can be employed and the corresponding buckling and postbuckling analysis can be performed. S8R is an eight noded shear deformable shell element with reduced integration, which allows large rotations and small strains. The number of shell elements which were used for the modelling of the cylindrical shells throughout this study was 2500 .

The first stage in the simulation is a linear eigenvalue buckling analysis. In simple cases, linear eigenvalue analysis may be sufficient for design evaluation; but geometrically nonlinear static problems sometimes involve buckling or collapse behaviour, where the load-displacement response shows a negative stiffness and the structure must release strain energy to remain in equilibrium. Several methods [35-39] are available for modelling such behaviour. One method is to treat the buckling response dynamically, therefore, modelling the response, with inertia effects included, as the structure snaps. This approach can be carried out by restarting the terminated static procedure and switching to a dynamic procedure when the static solution becomes unstable. Another approach for finding static equilibrium states, during the unstable phase of the response, is the modified RIKS method available in ABAQUS. The Riks method is based on moving with fixed increments along the static equilibrium path in a space defined by the displacements and a proportional loading parameter. This method is used for cases where the loading is proportional, therefore, the load magnitudes are governed by a single scalar parameter. Arc length methods such as the Riks method are global load-control methods that are suitable for global buckling and postbuckling analyses; they do not function well when buckling is localized. Another method is to use dashpots to stabilize the structure during a static analysis. ABAQUS offers an automated version of this stabilization 
approach for the static analysis procedures. This method has been successfully used in the earlier studies of the first author [4-5] for the analysis of delaminated composite shells where buckling is mostly localized.

In the current study the Riks method has been employed. It should be noted that the initial small deflection that is necessary to make the structure buckle was established by imposing an imperfection based on the first buckling mode. The imperfection amplitude varied from $0.01 t$ to $t$, where $t$ is the thickness of the shell.

Fig. 2 shows the first buckling mode of a graphite-epoxy cylindrical shell subject to axial compression, torsion, bending and external pressure, applied individually. The dimensions of the clamped shell are $\mathrm{L} / \mathrm{r}=5$ and $\mathrm{r} / \mathrm{t}=30$. For the lamina engineering constants of the selected materials throughout this study refer to Table 1.

In a recent study [4], the interaction buckling curve of the preceding laminated cylindrical shell with clamped ends subjected to simultaneous axial compression and external pressure, was obtained. The loading case of axial compression combined with internal pressure was also considered. In order to examine the effect of the stacking sequence on the buckling of delaminated cylinders, two different stacking sequences $[0 / 90 / 0]_{10 \mathrm{~T}}$, $\left[0_{2} / 90 / \pm 45 / \mp 45 / 90 / 0_{2}\right]_{2 \mathrm{~T}}$, respectively, were chosen for the analysis. For the stacking sequence of $[0 / 90 / 0]_{10 \mathrm{~T}}$, three different materials; graphite-epoxy, kevlar-epoxy and boronepoxy were considered. Fig. 3 shows the interaction buckling curves, relating pressure $\left(\mathrm{P} / \mathrm{P}_{\mathrm{c}}\right)$ and axial compressive load $\left(\mathrm{R} / \mathrm{R}_{\mathrm{c}}\right)$, through a range of values of $\mathrm{P}$, from buckling under external pressure $\left(P=P_{c}\right)$ to internal pressure $\left(P=-P_{c}\right)$, for the selected materials. $R_{c}$ and $\mathrm{P}_{\mathrm{c}}$ are the critical axial compressive load and critical external pressure of a perfect cylinder under axial compressive load alone and external pressure alone, respectively. The results show that for the selected materials, of the stacking sequence 1, the trends of the variation of the interaction curves are similar. Therefore, it can be concluded that the material properties do not have a significant influence on the variation of the interaction buckling curve. Next, the effect of the stacking sequence of the laminate on the shape of the interaction buckling curve was investigated. Fig.3 also shows the interaction buckling 
curve for the stacking sequence of $\left[0_{2} / 90 / \pm 45 / \mp 45 / 90 / 0_{2}\right]_{2 T}$ with the graphite-epoxy material properties. For the sake of brevity, and clarity of presentation, the results for the kevlar-epoxy and boron epoxy cylinders with the aforementioned stacking sequence were obtained but were not presented. However, they had similar trends as the interaction curve of the graphite-epoxy. By comparing the interaction buckling curves of the graphite-epoxy cylinder with the two different stacking sequences, it can be observed that the shape of the interaction buckling curve is mainly influenced by the stacking sequence. The difference between the interaction curves is less evident when the cylinder is subject to internal pressure and more apparent when the cylinder is subject to high level of external pressure. Fig. 4a shows the first buckling mode of the cylinder subject to combined axial compression and external pressure.

In this study the interaction buckling curves of the preceding cylinder with graphite-epoxy material properties and stacking sequence of $[0 / 90 / 0]_{10 \mathrm{~T}}$, for bending $\operatorname{moment}\left(\mathrm{M} / \mathrm{M}_{\mathrm{c}}\right)$ against pressure $\left(\mathrm{P} / \mathrm{P}_{\mathrm{c}}\right)$ and torsion $\left(\mathrm{T} / \mathrm{T}_{\mathrm{c}}\right)$ against pressure $\left(\mathrm{P} / \mathrm{P}_{\mathrm{c}}\right)$, are obtained $($ Fig. 5). The interaction buckling curve of the same cylinder, for axial compression $\left(R / R_{c}\right)$ against pressure $\left(\mathrm{P} / \mathrm{P}_{\mathrm{c}}\right)$, is also shown in Fig. 5. $\mathrm{M}_{\mathrm{c}}$ and $\mathrm{T}_{\mathrm{c}}$ are the critical buckling loads when the cylinder is subject to pure bending or pure torsion, respectively. It can be observed that the buckling curves of the bending vs pressure and axial compression vs pressure have similar trend of variation. However, the buckling curve for the torsion shows that the external pressure greatly reduces the critical torsional moment. Generally speaking, for the three buckling curves, the critical buckling load increases when the cylinder is subjected to internal pressure and the critical load has almost a linear variation with respect to the increase of the internal pressure. Figs. $4 \mathrm{~b}$ and $4 \mathrm{c}$ show the first buckling mode of the cylinder subject to combined bending-external pressure and torsion-external pressure, respectively.

In a study by Simitses el al [21], the nonlinear analysis of imperfect metallic and laminated cylinders under bending and axial compression, using the finite element analysis, was carried out. In their paper they have presented interactive buckling curves, axial compression vs bending, of a boron-epoxy cylindrical shell $(\mathrm{L} / \mathrm{r}=1.0$ and $\mathrm{r} / \mathrm{t}=354)$ with the 
stacking sequence of [45/-45] . Fig. 6-i shows the buckling curve produced by Simiteses et al in reference [21] which has a linear variation. Fig. 6-i also shows the buckling curve, axial compression vs bending, of the same cylinder obtained in this study. It can be observed that the relationship between critical loads of cylinders under compression and bending is almost linear except those of the laminated cylinder under a very high compression load.

Meyer-Piening et al [30] presented the buckling loads of Carbon Fibre Reinforced Polymer[CFRP] composite cylinders under combined axial and torsion loadings. In their work they have compared their experimental results with the corresponding analytical results. Here the FE results of the current study have been compared with the corresponding analytical solution. Fig. 6-ii shows the interactive buckling curves for a CFRP composite cylindrical shell $(\mathrm{L} / \mathrm{r}=2.04$ and $\mathrm{r} / \mathrm{t}=200)$ with the stacking sequence of $[ \pm 53 / \pm 38 / \pm 22 / \pm 90 / \pm 30]$ used by Meyer-Piening et al and also the buckling curve obtained in this study. It can be observed that the trends of variation of both results are similar. However, the FE results show slightly higher buckling loads than the analytical solution.

Next, the linear buckling analysis was performed on a graphite epoxy cylindrical shell $\left[\mathrm{L} / \mathrm{r}=5, \mathrm{r} / \mathrm{t}=30\right.$ and $\left.(0 / 90 / 0)_{10 \mathrm{~T}}\right]$ subject to axial compression, bending and external pressure. Each analysis was performed in three different steps. For each combined loading case, initially a live pressure load was applied to the shell, then a bending moment was applied to the pressurized shell in the second step and in the final step the critical axial compressive load was determined. Using ABAQUS it is also possible to apply the bending moment in the first step and the pressure in the second step and finally determine the critical axial compressive load.

Fig. 7 shows the interaction buckling curves, axial compression $\left(R / R_{c}\right)$ vs bending $\left(M / M_{c}\right)$, at different pressure levels. The pressure level varies from $-0.75 P_{c}$ to $0.93 \mathrm{P}_{\mathrm{c}}$. It can be seen that the internal pressure increases the critical buckling load and onset of the buckling mode. However, for high values of the external pressure the critical buckling load decreases dramatically. The buckling curves for the pressure level of $\mathrm{P}<0.5 \mathrm{Pc}$ are almost 
linear except those of the laminated cylinder under very high compression load. The buckling curves for the pressure levels of $\mathrm{P}>0.5 \mathrm{Pc}$ have a parabolic shape.

A similar set of results has also been obtained for the combined loadings of axial compression, torsion and lateral pressure. Fig. 8 shows the interaction buckling curves, axial compression $\left(\mathrm{R} / \mathrm{R}_{\mathrm{c}}\right)$ vs torsion $\left(\mathrm{T} / \mathrm{T}_{\mathrm{c}}\right)$, at pressure levels varying from $-0.75 P_{c}$ to $0.93 \mathrm{P}_{\mathrm{c}}$. It can be seen that the internal pressure increases the critical buckling load and onset of the buckling mode. However, for high values of the external pressure the critical buckling load decreases drastically. It can be observed that for the pressure level of $\mathrm{P}>0$. each buckling curve consists of two lines intersecting at $\mathrm{T} / \mathrm{T}_{\mathrm{c}} \approx 0.4$. For $\mathrm{T} / \mathrm{T}_{\mathrm{c}}>0.4$ the rise of the internal pressure slightly increases the critical axial load. This rate of increase is relatively higher for $\mathrm{T} / \mathrm{T}_{\mathrm{c}}<0.4$.

Fig. 9a shows the first buckling mode of a graphite epoxy cylinder subject to axial compression, bending and external pressure. Fig. $9 \mathrm{~b}$ shows the first buckling mode of the same cylinder subject to axial compression, torsion and external pressure.

Next, the postbuckling analysis was performed. The imperfection amplitude varied from 0.01t to 1t. Fig. 10 shows the load-shortening response $\left(R / R_{c} v s U_{x} / t\right)$ of the preceding cylinder when it is subject to axial compression alone. The effect of geometric imperfection is clearly evident. It can be observed that for a small imperfection amplitude, the critical load can be significantly greater than the critical buckling load of the perfect cylinder subject to the same loading conditions. For larger imperfection amplitudes, initially the evolution of the displacements produced by the applied load is very smooth but as soon as the global instability develops the displacements dramatically increase with the increase applied axial compressive load, indicating the complete loss of load-carrying capacity of the structure.

Fig. 11 shows the bending moment $\left(\mathrm{M} / \mathrm{M}_{\mathrm{c}}\right)$ vs end rotation $\left(\psi_{\mathrm{y}}\right)$ of the preceding cylinder when it is subject to the bending moment alone. The results show that for a small imperfection amplitude, the critical buckling load is almost the same as the critical 
buckling load of a perfect cylinder. Obviously for larger imperfection amplitudes the critical buckling load drops sharply, however, in comparison with the axial loading case the cylinder subject to bending is less imperfection sensitive.

Fig. 12 shows the torsion $\left(\mathrm{T} / \mathrm{T}_{\mathrm{c}}\right)$ vs angle of twist $\left(\psi_{\mathrm{x}}\right)$ of the above cylinder when it is subject to torsion alone, for different imperfection amplitudes. The results show that the cylinder has almost the same response, irrespective of the imperfection amplitude. Therefore, it can be said that when the cylinder is subject to torsion alone it is virtually imperfection-insensitive. This agrees with the analytical results of Simitses el al [17] and experimental results of Meyer-Piening et al [30].

Next, the postbuckling response of the above cylinder subject to combined axial compression and bending moment was obtained. For each combined loading case, initially a live bending moment was applied to the shell, then the axial compressive load was set to increase up to 1.2 times the critical axial compressive load of a perfect cylinder, subjected to axial compressive load alone. Figs. 13a, b and c show the load-shortening response $\left(R / R_{c}\right.$ vs $\left.U_{x} / t\right)$ of the cylinder subject to the preloading of $0.1 \mathrm{M}_{c}, 0.2 \mathrm{M}_{\mathrm{c}}$ and $0.4 \mathrm{M}_{\mathrm{c}}$, respectively. A similar set of results are obtained for the cylinder subject to combined axial compression and torsion. For each combined loading case, initially a live torsion was applied to the shell, then the axial compressive load was set to increase up to 1.2 times the critical axial compressive load of a perfect cylinder, subjected to axial compressive load alone. Figs. 14a, b and c show the load-shortening response $\left(R / R_{c} v s U_{x} / t\right)$ of the cylinder subject to the preloading of $0.1 \mathrm{~T}_{\mathrm{c}}, 0.2 \mathrm{~T}_{\mathrm{c}}$ and $0.4 \mathrm{~T}_{\mathrm{c}}$, respectively. Fig. 15-a compares the postbuckling response of the cylinder subject to combined axial compression and bending, for the imperfection amplitudes of $0.01 \mathrm{t}$ and $0.5 \mathrm{t}$, for the preloadings of $0.1 \mathrm{M}_{\mathrm{c}}, 0.2 \mathrm{M}_{\mathrm{c}}$ and $0.4 \mathrm{M}_{\mathrm{c}}$, respectively. Fig. 15-b compares the postbuckling response of the cylinder subject to combined axial compression and torsion, for the imperfection amplitudes of $0.01 \mathrm{t}$ and $0.5 \mathrm{t}$, for the preloadings of $0.1 \mathrm{~T}_{\mathrm{c}}, 0.2 \mathrm{~T}_{\mathrm{c}}$ and $0.4 \mathrm{~T}_{\mathrm{c}}$, respectively. Figs. $16 \mathrm{a}$ and $16 \mathrm{~b}$ show the collapse load of the cylinder with respect to the increase of the imperfection amplitude, for the combined axial compression-bending and axial compression-torsion cases, 
respectively. The collapse load is the maximum load which the structure can support. The following observations have been made from this study.

The results show that for the lower values of the preloading and imperfection amplitudes of less than 0.1t, the response of the shell is almost imperfection-insensitive. For the large values of the preloading and large imperfection amplitudes, the prebuckling stiffness drops drastically, the structure becomes imperfection-sensitive and the postbuckling response becomes more stable. The stability of the postbuckling response of the cylinder subject to combined axial compression and torsion is more apparent. It can also be observed that for the combined axial compression and torsion, for small imperfection amplitudes, the elastic limit of the axial compressive load is almost independent of the value of the preload. For the case of combined axial compression and bending, the collapse load decreases with the increase of the imperfection amplitude and the preloading value. For the case of combined axial compression and torsion, for the same preloading value, the collapse load decreases with the increase of the imperfection amplitude. However, for the same imperfection amplitude the collapse load increases with the increase of the preloading value.

\section{CONCLUDING REMARKS}

Computational analysis using the finite element method has been carried out to study the response of perfect and imperfect composite cylindrical shells under combined loading. The interaction buckling curves of perfect composite shells subject to different combinations of axial compression, bending, torsion and lateral pressure are obtained. The postbuckling analysis of composite cylinders with geometric imperfections of eigenmode shape is carried out to investigate the effect of imperfection amplitude on the critical buckling load.

The results show that a very small imperfection amplitude does not appreciably alter the critical load of a perfect geometry under the same loading condition. For the combined loading case, it was observed that the internal pressure increases the critical buckling load and onset of the buckling mode. For high values of external pressure, the critical buckling load decreases dramatically. The results show that under torsion, laminated 
cylindrical shells are less sensitive to geometric imperfections than they are under compression or bending. It was observed that the shape of interaction buckling curves depends significantly on the laminate stacking sequence. Consequently, a laminate can be tailored depending on its loading conditions to resist buckling and postbuckling collapse.

The results show that the elastic limit load can be achieved only for very small imperfection amplitudes and in such a case, imperfection sensitivity can be predicted. When the magnitude of the initial imperfection amplitude becomes larger, the prebuckling stiffness decreases dramatically and the postbuckling path becomes stable. It was observed that the effects of imperfections are more apparent when the composite cylindrical shells are subject to combined loadings.

It is shown that computationally generated design curves can summarize the initial buckling loads of composite shell structures subject to combined loading. The curves should be useful for future design of shell structures subject to complex loading conditions. However, more research is needed to establish generally applicable, safe and correct guidelines for a purely numerical buckling design.

The modelling approach established in this work offers high potential for further development. So far, the material properties are assumed to be linear. However, the structure of the model offers convenient extension to nonlinear behaviour. In this study, only the geometric imperfections are considered. Therefore, it would be desired to study the imperfections including shell-wall thickness variations and local shell-wall ply gaps associated with the manufacturing process. The non-uniform distribution of the applied loads and various boundary conditions can also be studied. 
Tafreshi, A. \& Bailey, Colin G., Sep. 2007 In : Composite Structures. 80, 1, p. 49-64 16 p.

\section{REFERENCES}

1) Tafreshi, A., "Optimum shape design of composite structures using the boundary element method", AIAA Journal, 2005; 43(6), 1349-1359

2) Tafreshi, A., "Shape optimization of anisotropic structures using the boundary element method", Journal of Strain Analysis, 2003; 3(38): 219-32

3) Tafreshi, A., "Shape design sensitivity analysis of $2 \mathrm{D}$ anisotropic structures using the boundary element method", Engineering Analysis with Boundary Elements, 2002; 26: 237-51

4) Tafreshi, A. "Delamination buckling and post-buckling analysis of composite cylindrical shells subject to axial compression and external pressure", Composite structures, 2006;72(4):401-18

5) Tafreshi, A., "Delamination buckling and postbuckling in composite cylindrical shells under external pressure", Thin-walled structures, 2004; 42/10:1379-1404

6) Tafreshi, A., "Efficient modelling of delamination buckling in composite cylindrical shells under axial compression", Composite structures, 64(2004), 511-520

7) Jaunky, N., Knight N.F. Jr, "An assessment of shell theories for buckling of circular cylindrical laminated composite panels loaded in axial compression”, International Journal of Solids and Structures, 1999; 36: 3799-820

8) Jaunky, N., Knight, N.F. Jr and Ambur, D.R., "Buckling analysis of anisotropic variable-curvature panels and shells", Composite Structures, 1999; 43: 321-29 
Tafreshi, A. \& Bailey, Colin G., Sep. 2007 In : Composite Structures. 80, 1, p. 49-64 16 p.

9) Chaplin, C.P. and Palazotto, A.N., "The collapse of composite cylindrical panels with various thickness using finite element analysis", Computers and Structures, 1996; 60(N5): 797-815

10) Rezeepazhand, J., Simitses, G.J. and Starnes, J.H. Jr, "Scale models for laminated cylindrical shells subjected to axial compression", Composite Structures, 1996; 34: $371-9$

11) Hilburger, M.W. and Starnes Jr, J.H., "Effects of imperfections on the buckling response of compression-loaded composite shells", Int. J. of non-linear mechanics, 2002; 37(4-5): 623-43

12) Hilburger, M.W. and Starnes J.H. Jr., "Effects of imperfections of the buckling response of composite shells", thin-walled structures, 2004; 42(3), 369-397

13) Xue, J. and Fatt, H., "Buckling of a non-uniform, long cylindrical shell subjected to external hydrostatic pressure", Engineering Structures, 2002; 24:1027-1034

14) Messager, T., Pyrz, M. Gineste, B. and Chauchot, P., "Optimal laminations of thin underwater composite cylindrical vessels”, Composite Structures, 2002; 58: 529-37

15) Xue, J. and Hoo Fatt, M.S., "Buckling of non-uniform, long cylindrical shell subjected to external hydrostatic pressure", Engineering structures, 2002; 24, 10271034

16) Anastasiadis, J.S., and Simitses, G.J., "Buckling of pressure-loaded, long, shear deformable, cylindrical laminated shells", Composite structures, 1993; 23, 221-231

17) Simitses, G.J. , Shaw, D. and Sheinman, I., "Imperfection sensitivity of laminated cylindrical shells in torsion and axial compression", Composite structures, 1985;4, $335-360$ 
18) Winterstetter, Th. A. and Schmidt, H., "Stability of circular cylindrical shells under combined loading”, Thin-walled structures, 2002; 40, 893-909

19) Simitses, G.J., "Buckling and postbuckling of imperfect cylindrical shells: a review, Applied Mech. Rev., 1986; 39(10), 1517-1524

20) Arbocz, J., "The effect of initial imperfections on shell instability", in: Y.C.Fung, E.E.Scheler(Eds.), Thin-shell structures, Prentice-Hall, Inc., Englewood Chiffs, NJ, $1974,205-245$

21) Huyan, X., Simitses, G.J. and Tabiei, A., "Nonlinear analysis of imperfect metallic and laminated cylinders under bending loads", AIAA Journal, 1996; 34(11), 24062413

22) Anastasiadis, J.S., Tabiei, A. and Simitses, G.J., "Instability of moderately thick, laminated, cylindrical shells under combined axial compression and pressure", Composite structures, 1994; 27:367-78

23) Tafreshi, A., "Buckling and post-buckling analysis of composite cylindrical shells with cutouts subjected to internal pressure and axial compression loads" International Journal of Pressure Vessels and Piping, 2002; 79(5): 351-359

24) Shen H.S., "Postbuckling of shear deformable cross-ply laminated cylindrical shells under combined external pressure and axial compression", International Journal of Mechanical Sciences, 2001; 43: 2493-523

25) Adali, S., Verijenko, V.E. and Richter, A., "Minimum sensitivity design of laminated shells under axial load and external pressure", Composite structures, 2001; 54: $139-142$ 
Tafreshi, A. \& Bailey, Colin G., Sep. 2007 In : Composite Structures. 80, 1, p. 49-64 16 p.

26) Featherston, C.A., "Imperfection sensitivity of curved panels under combined compression and shear", International journal of non-linear mechanics", 2003; 38: $225-238$

27) Simitses, G.J., "Instability of orthotropic cylindrical shells under combined torsion and hydrostatic pressure", AIAA J, 1967, 5(8): 1463-9

28) Bisagni, C. and Cordisco P., "An experimental investigation into the buckling and postbuckling of CFRP shells under combined axial and torsion loading", Composite structures, 2003;60: 391-402

29) Nemeth, M.P., Young R.D., Collins, T.J. and Starnes, J.H, Jr, "Effects of initial geometric imperfections on the non-linear response of the space shuttle superlightweight liquid-oxygen tank", International journal of non-linear mechanics, $37,2002,723-744$

30) Meyer-Piening H.R., Farshad, M., Geier, B. and Zimmermann R., "Buckling loads of CFRP composite cylinders under combined axial and torsion loading-experiments and computations", Composite structures 53, 2001, 427-435

31) Stein M. ,'Some recent advances in the investigation of shell buckling", AIAA J, $1968 ; 6: 2239-45$

32) Arbocz, J., “The imperfection data bank, a means to obtain realistic buckling loads. In Ramm E., Buckling of shells. Stuttgart, Germany, 1982

33) Tafreshi, A.,"Numerical analysis of thin torispherical end closures", International Journal of Pressure Vessels and Piping, 1997; 71: 77-88 
Tafreshi, A. \& Bailey, Colin G., Sep. 2007 In : Composite Structures. 80, 1, p. 49-64 16 p.

34) Tafreshi, A. and Thorpe, T.E., "Effects of local departures from nominal dimensions on stresses in thin torispherical end-closures", Journal of Strain Analysis,1996; 31(4): $315-24$

35) ABAQUS User's Manual, Version 6.4, Hibbit, Karlson and Sorenson

36) Riks, E., "The application of Newton's method to the problem of elastic stability", J. Appl. Mech., 1972; 39: 1060-6

37) Riks, E., Rankin C.C., Brogan F.A. "On the solution of mode jumping phenomena in thin-walled shell structures", Comput/Meth Appl Mech Engng, 1996: 59-62

38) Powell G and Simons J., "Improved iterative strategy for nonlinear structures", Int. J. Numer Meth Engng, 1981; 17:1455-67

39) Ramm E., "Strategies for tracing the nonlinear response near limit points. In: Wunderlich E, Stein E, Bathe K.J. editors. Nonlinear Finite element Analysis in Structural Mechanics. Berlin: Springer, 1981 


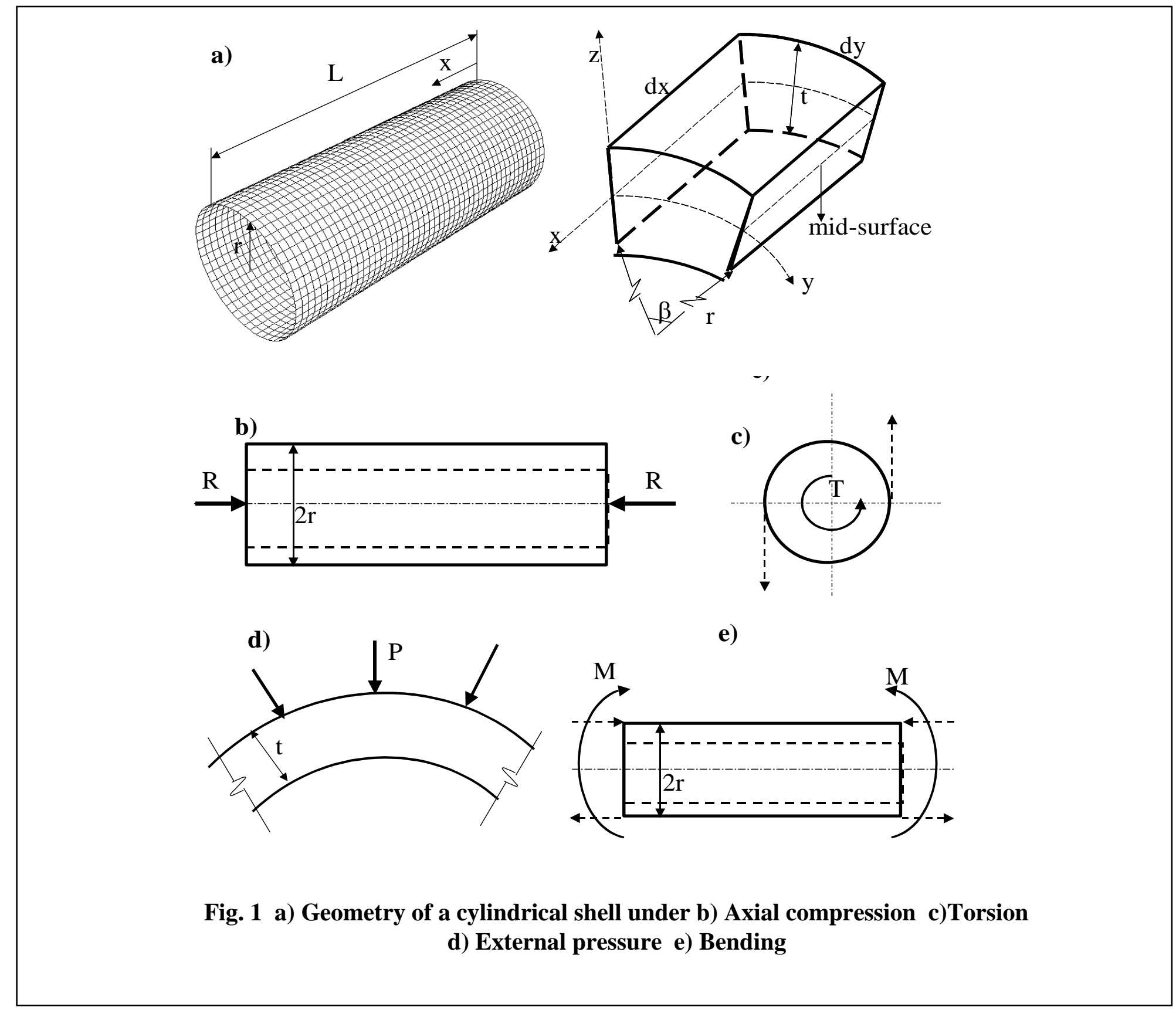


Tafreshi, A. \& Bailey, Colin G., Sep. 2007 In : Composite Structures. 80, 1, p. 49-64 16 p.

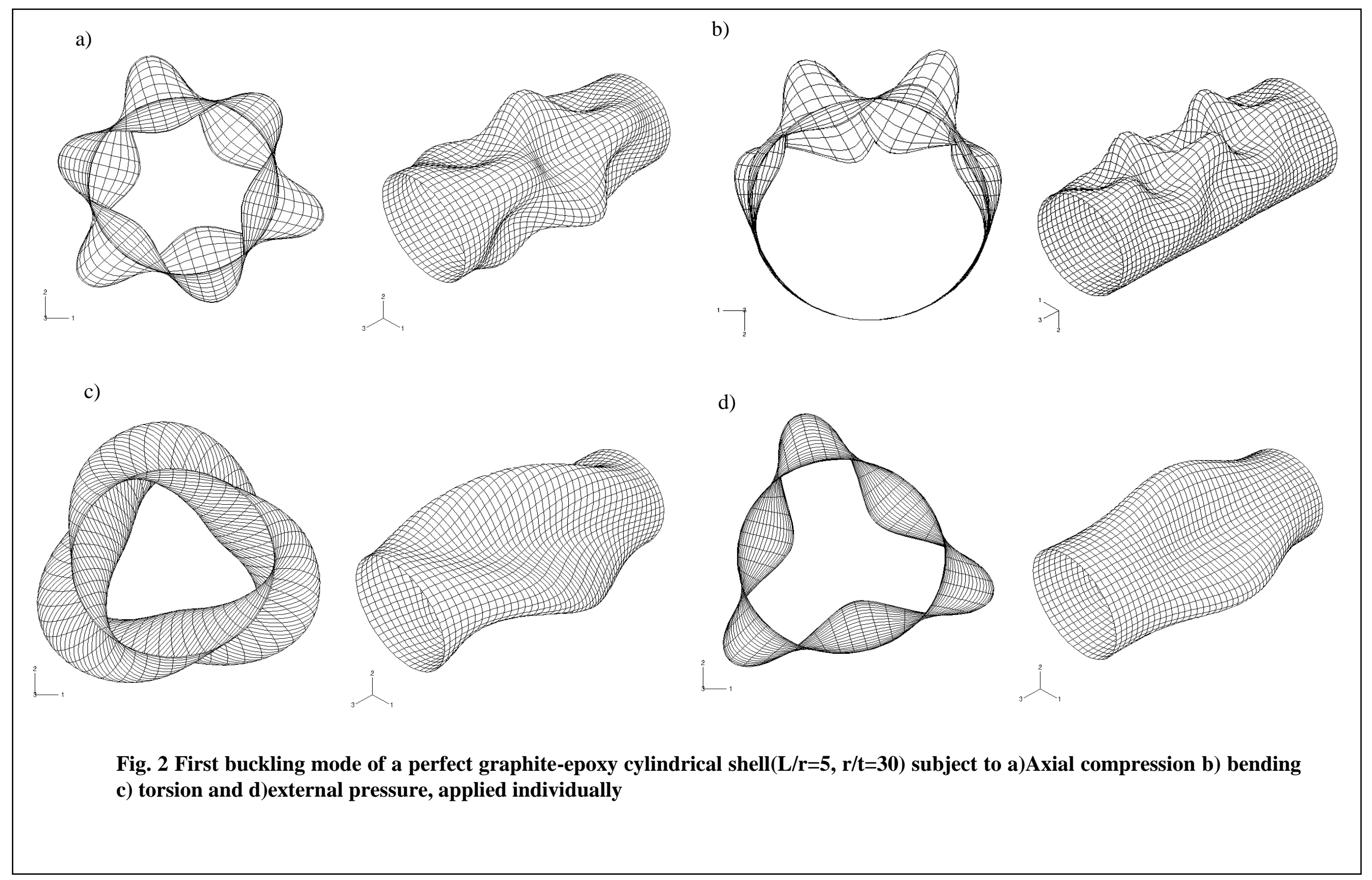


Fig. 3 Interaction buckling curve of a perfect cylindrical shell subject to combined axial compression and pressure( $L / r=5, r / t=30)$, [Ref. 4]

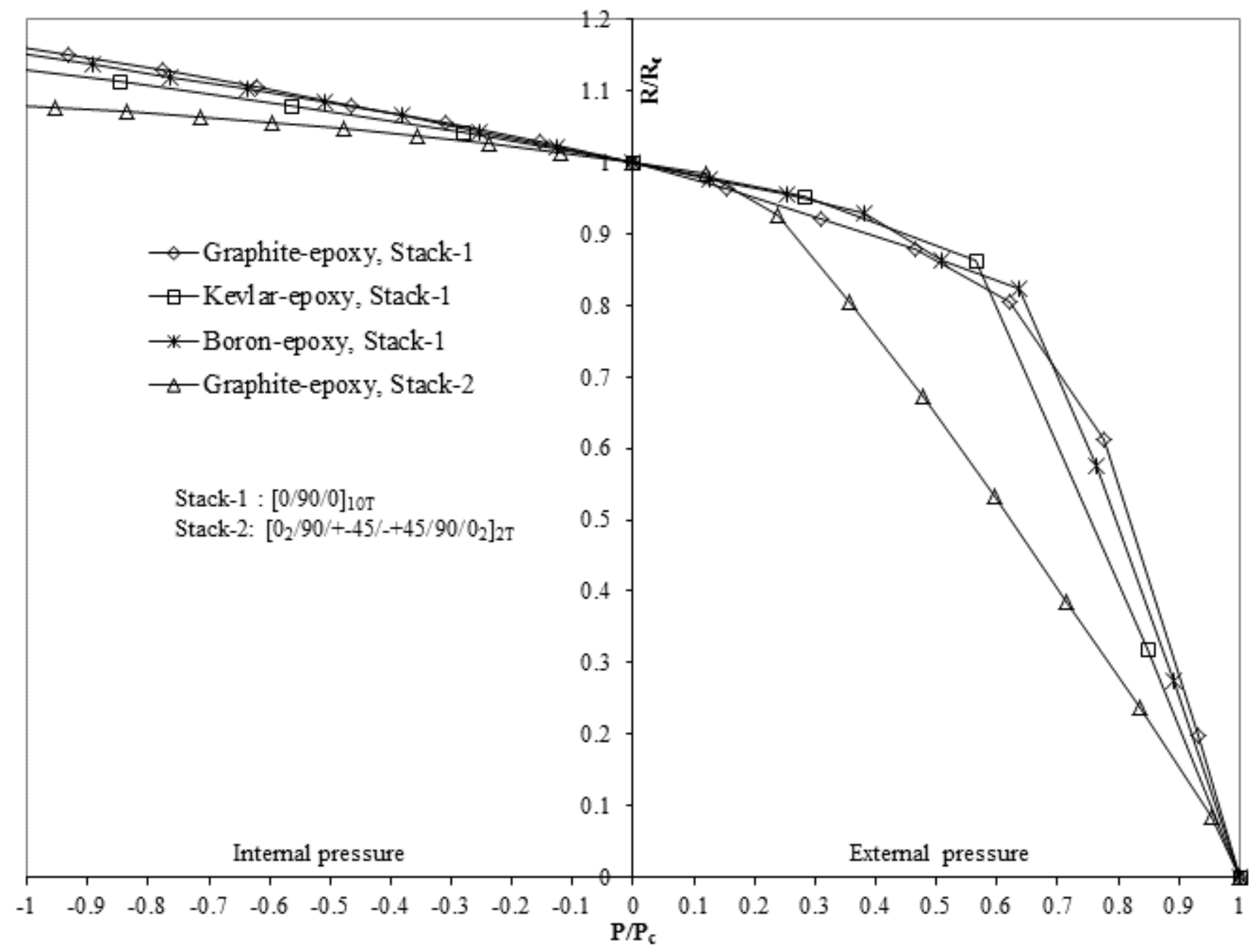




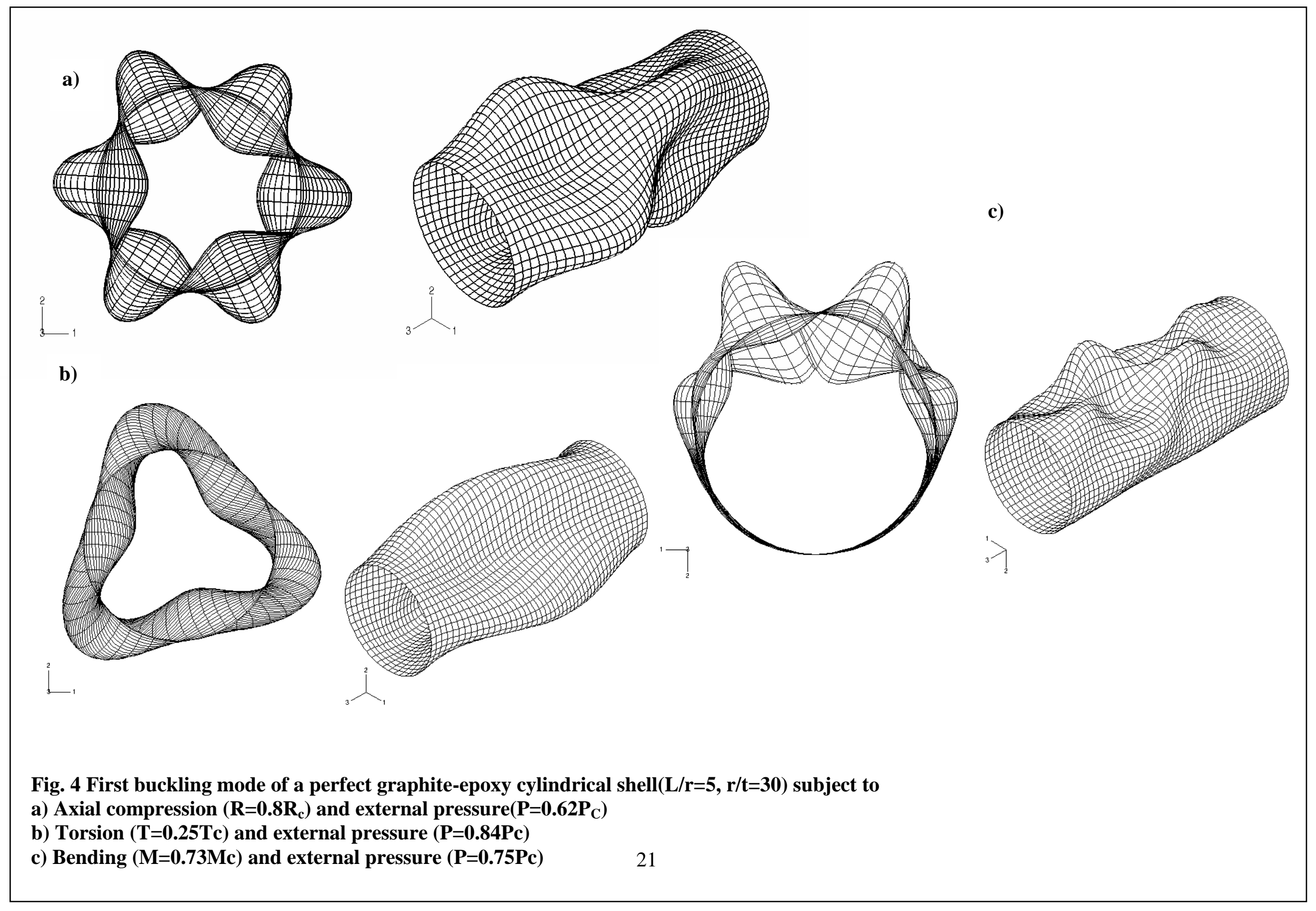


Fig. 5 Interaction buckling curves of a perfect graphite epoxy cylindrical shell $(\mathrm{L} / \mathrm{r}=5$, $r / t=30)$ subject to combined a) axial compression and pressure [Ref.4]

b) bending and pressure c)torsion and pressure

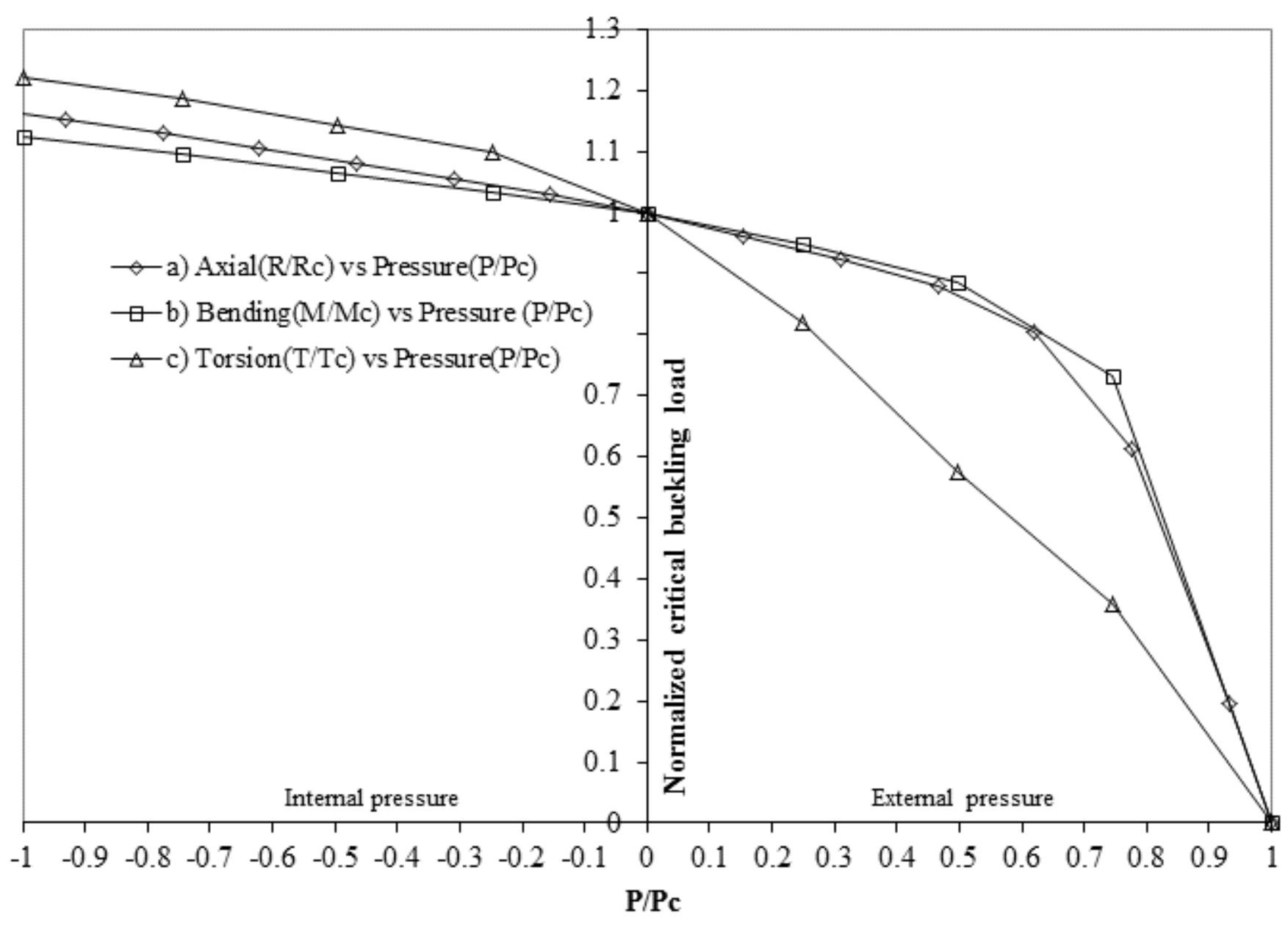




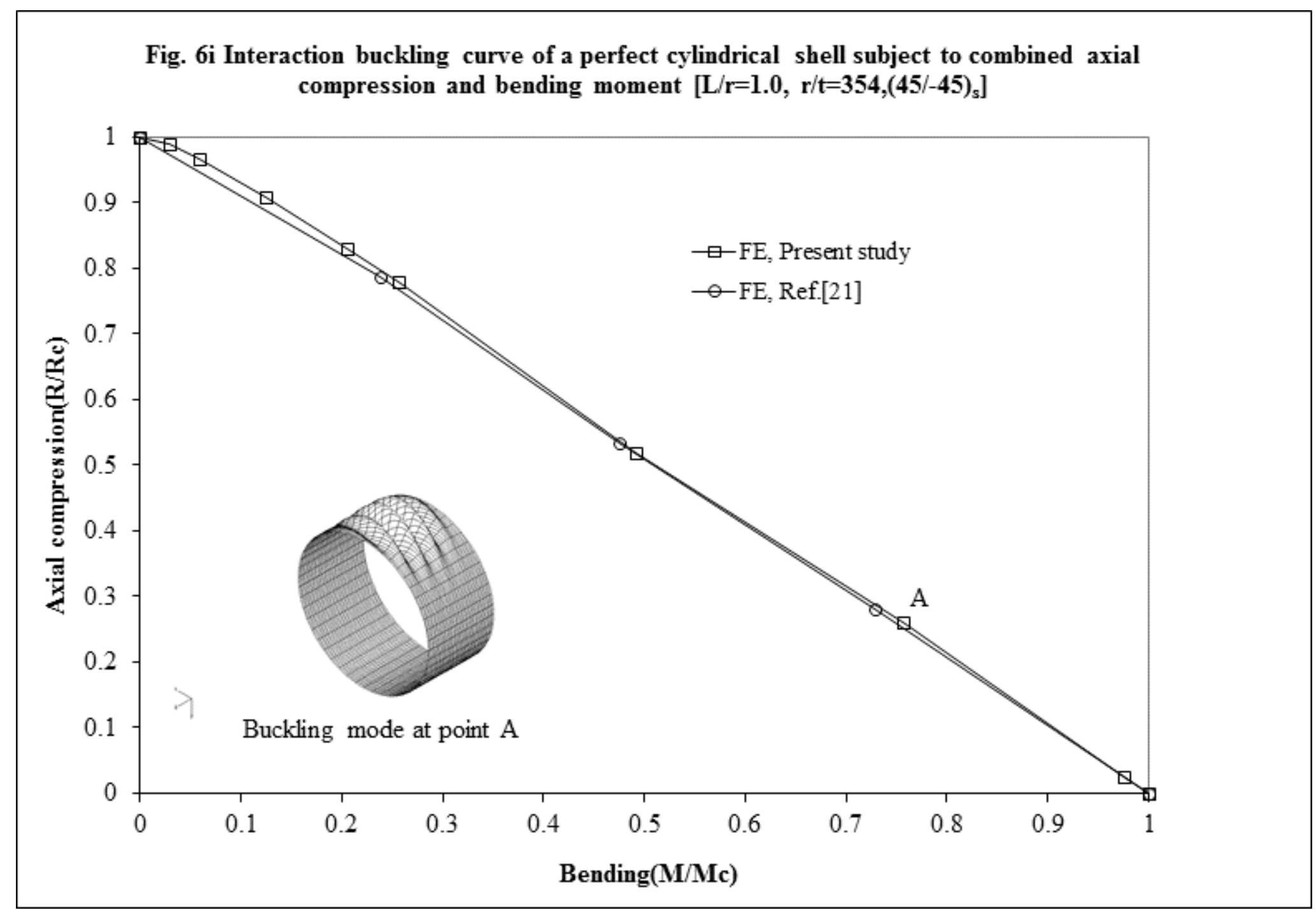




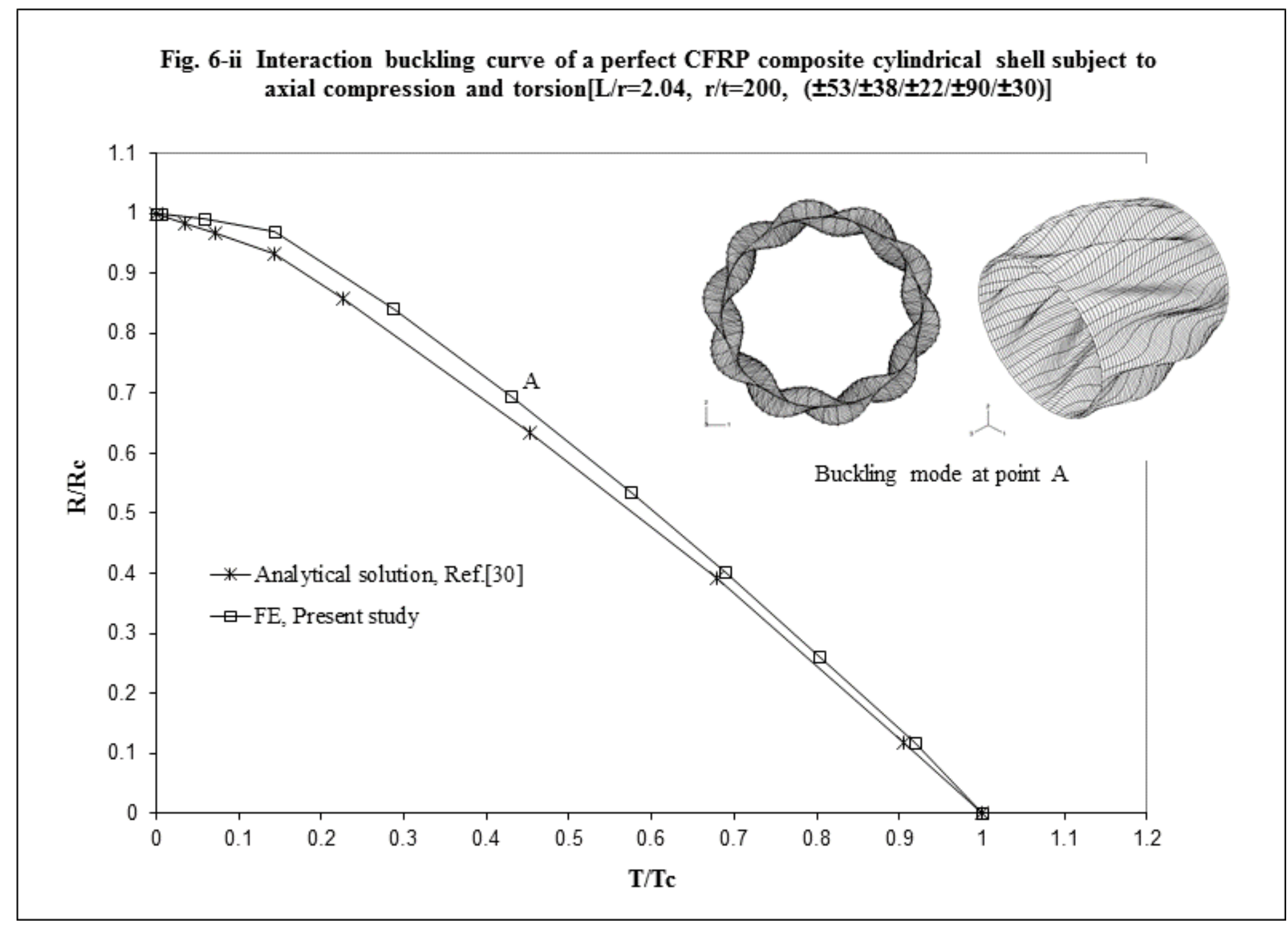




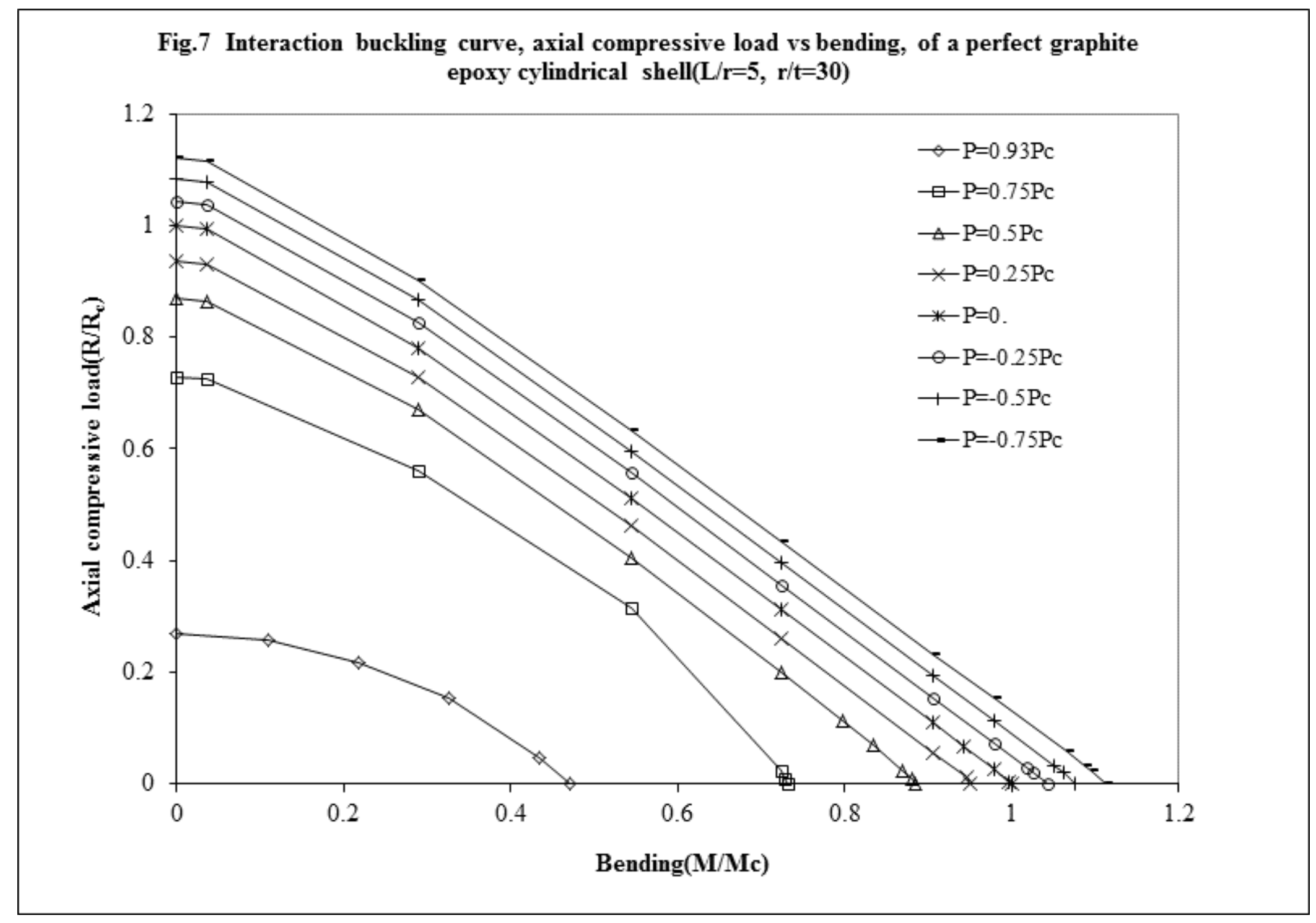




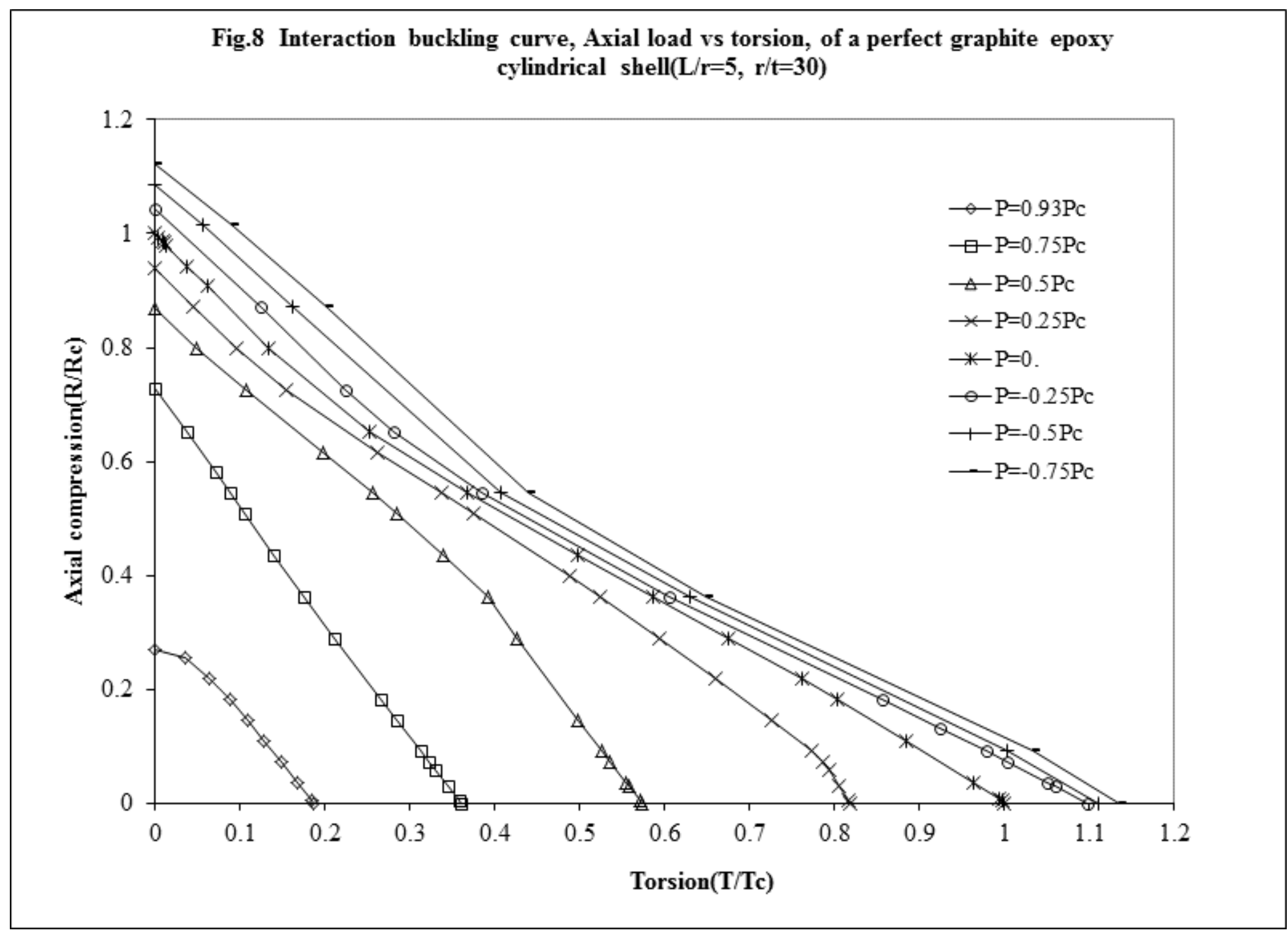


a)
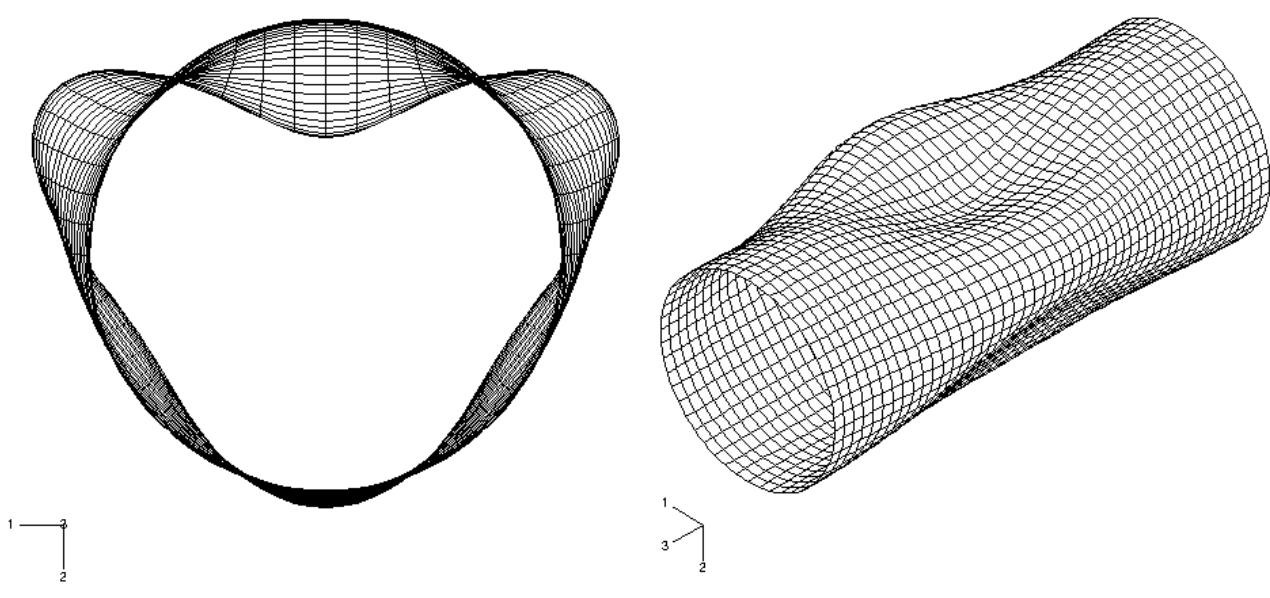

b)
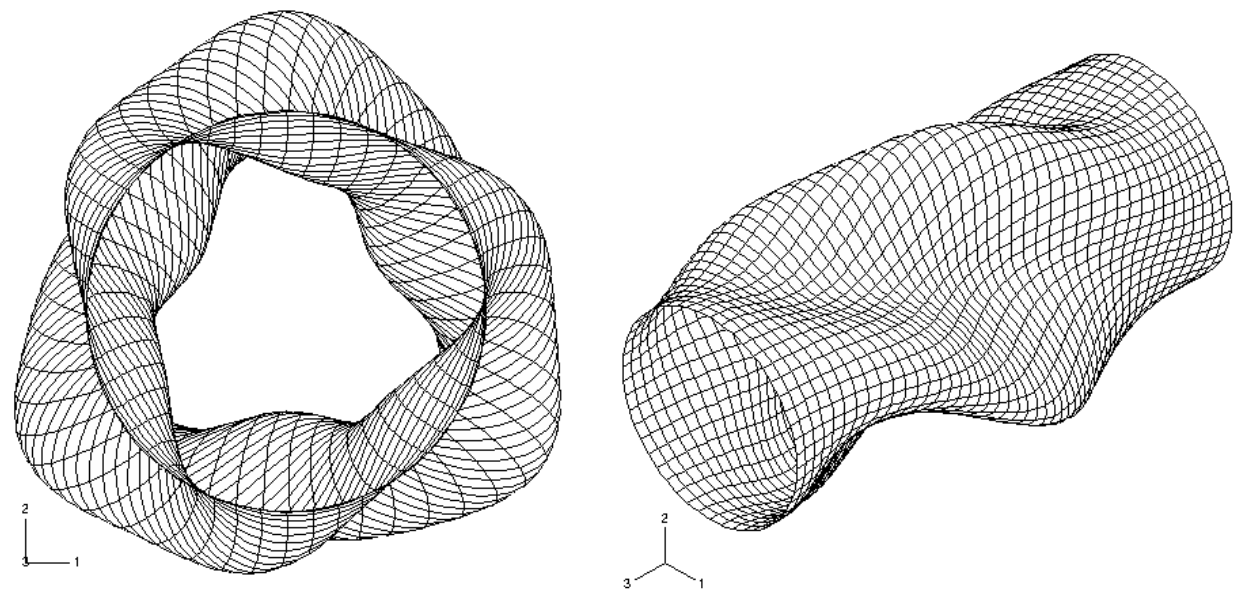

Fig. 9 First buckling mode of a perfect graphite-epoxy cylindrical $\operatorname{shell}(\mathrm{L} / \mathrm{r}=5, \mathrm{r} / \mathrm{t}=30)$ subject to a)Axial compression $\left(R=0.54 R_{c}\right)$, bending $(M=0.3 M c)$ and external pressure $\left(P=0.75 P_{C}\right)$

b) Axial compression $\left(R=0.72 R_{c}\right)$, Torsion $(T=0.1 T c)$ and external pressure $(P=0.375 P c)$ 


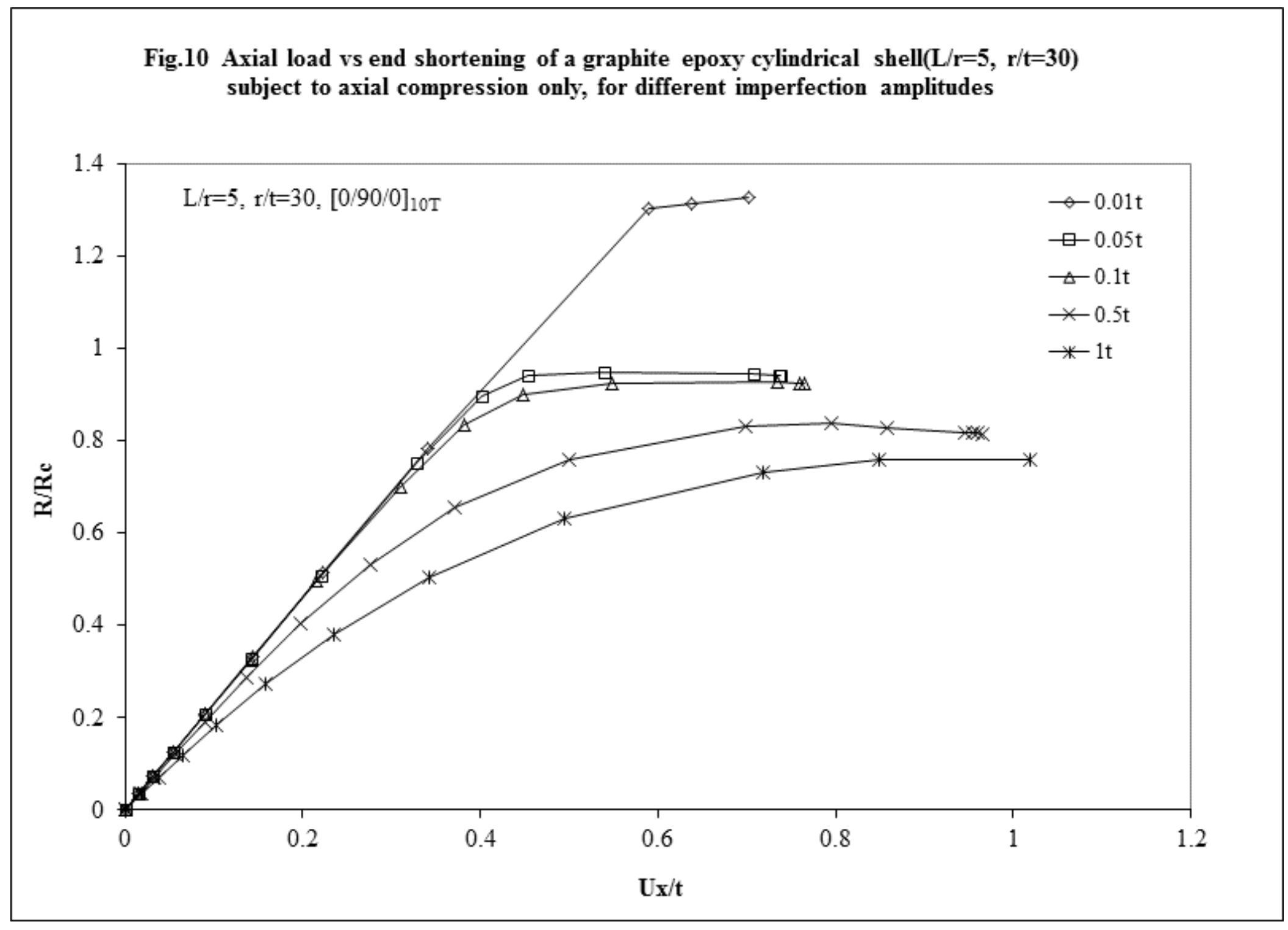




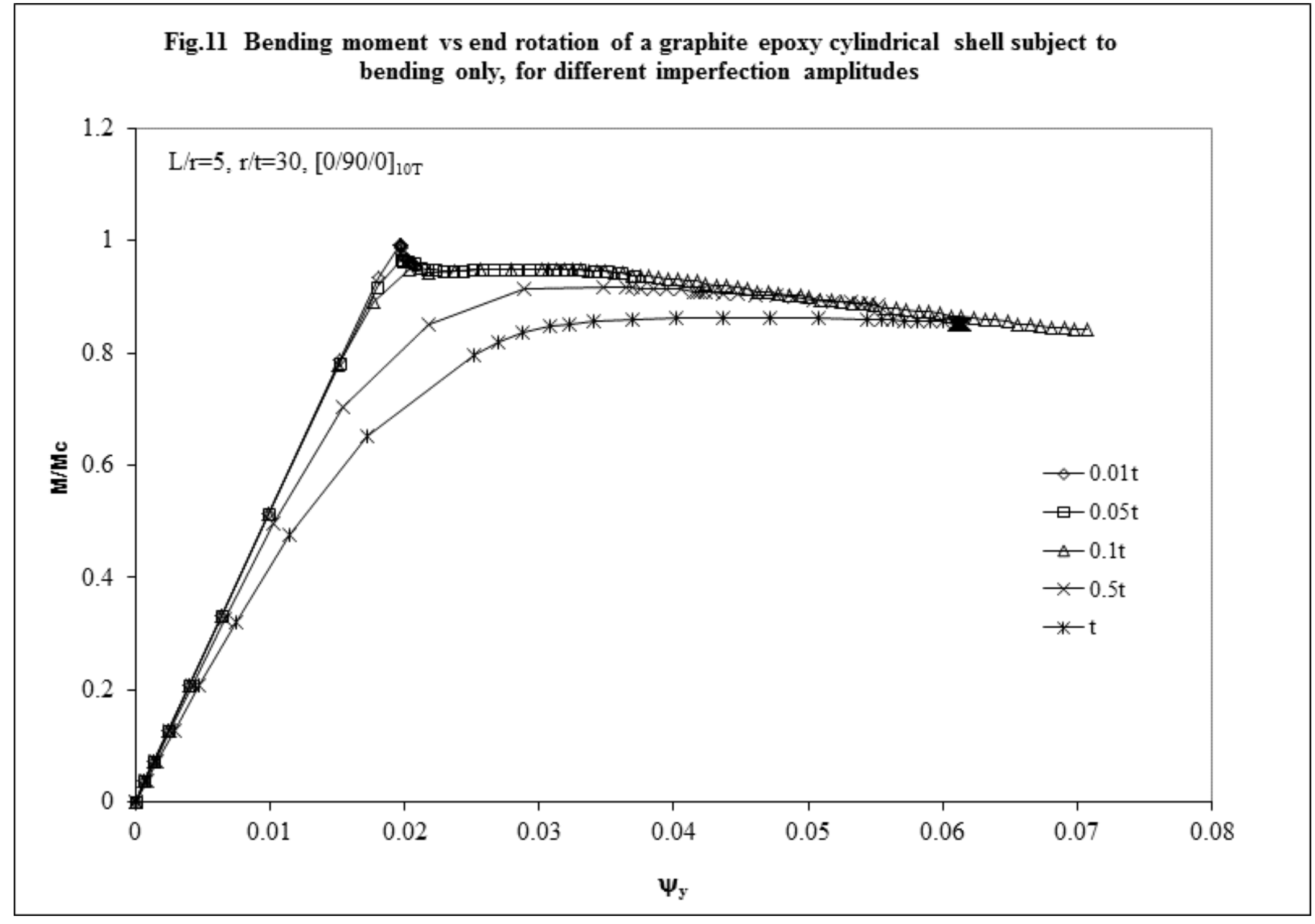




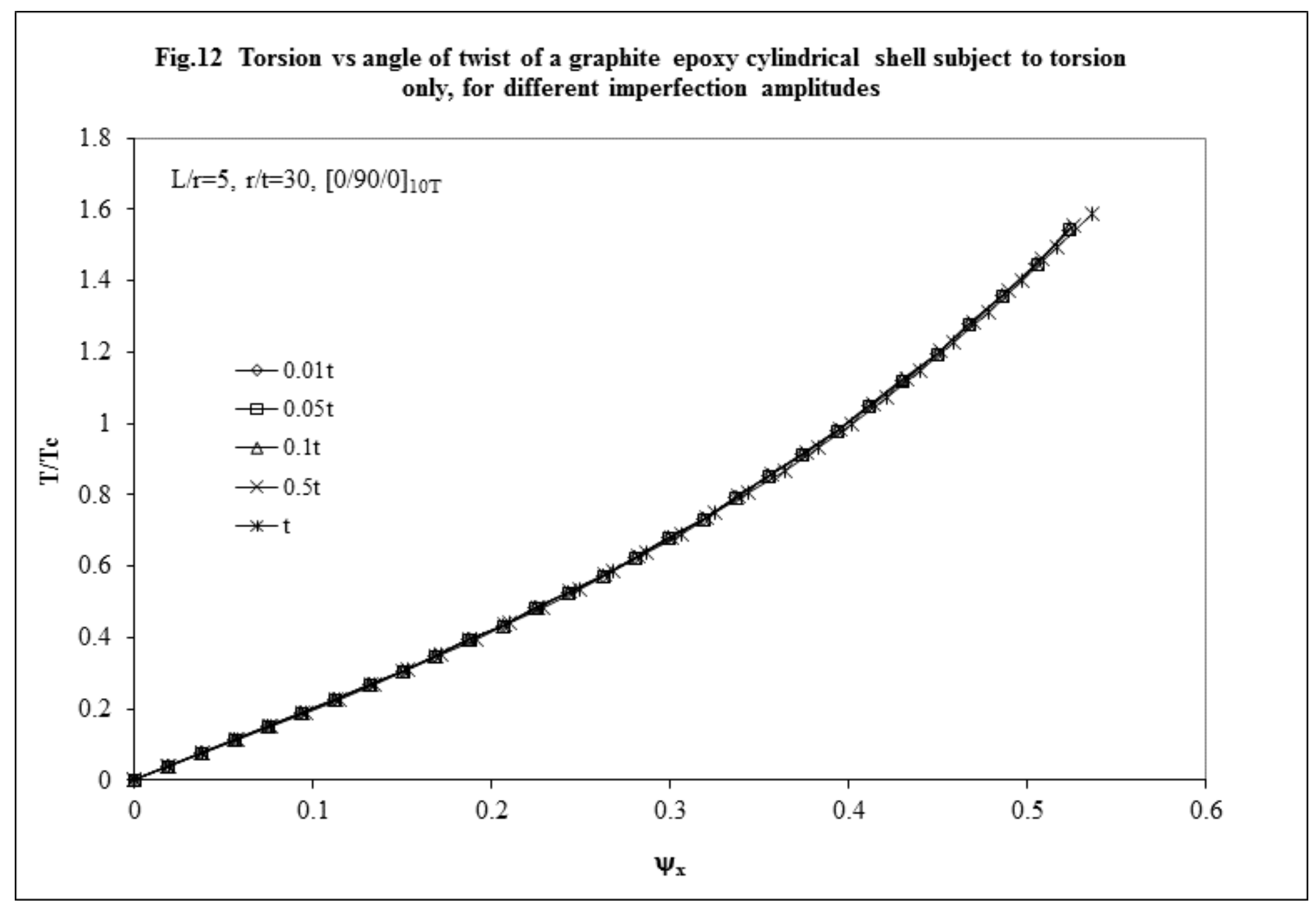



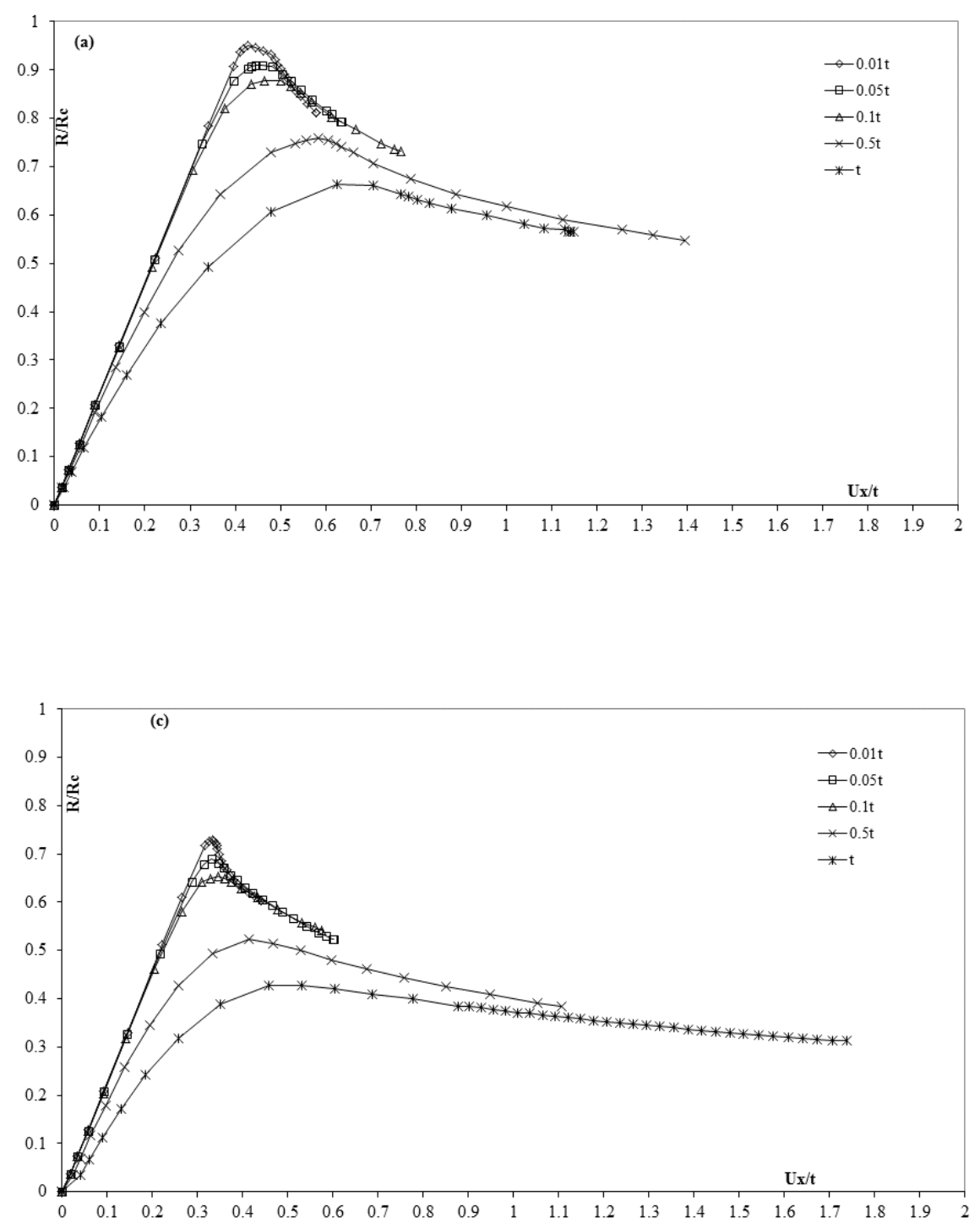

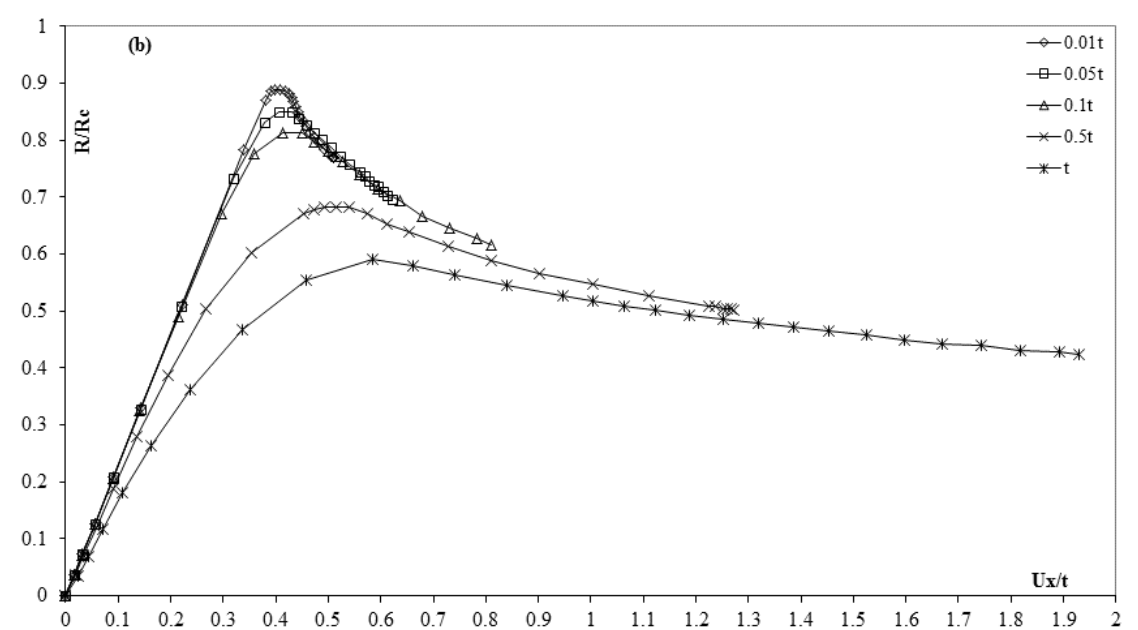

Fig. 13 Axial compressive load vs end shortening of a graphite epoxy cylindrical shell for different initial imperfection amplitudes, with a preloading of a) $M=0.1 M c \quad b) M=0.2 M c \quad c) M=0.4 M c$ $\mathrm{L} / \mathrm{r}=5, \mathrm{r} / \mathrm{t}=30,[0 / 90 / 0]_{\mathrm{s}}$ 

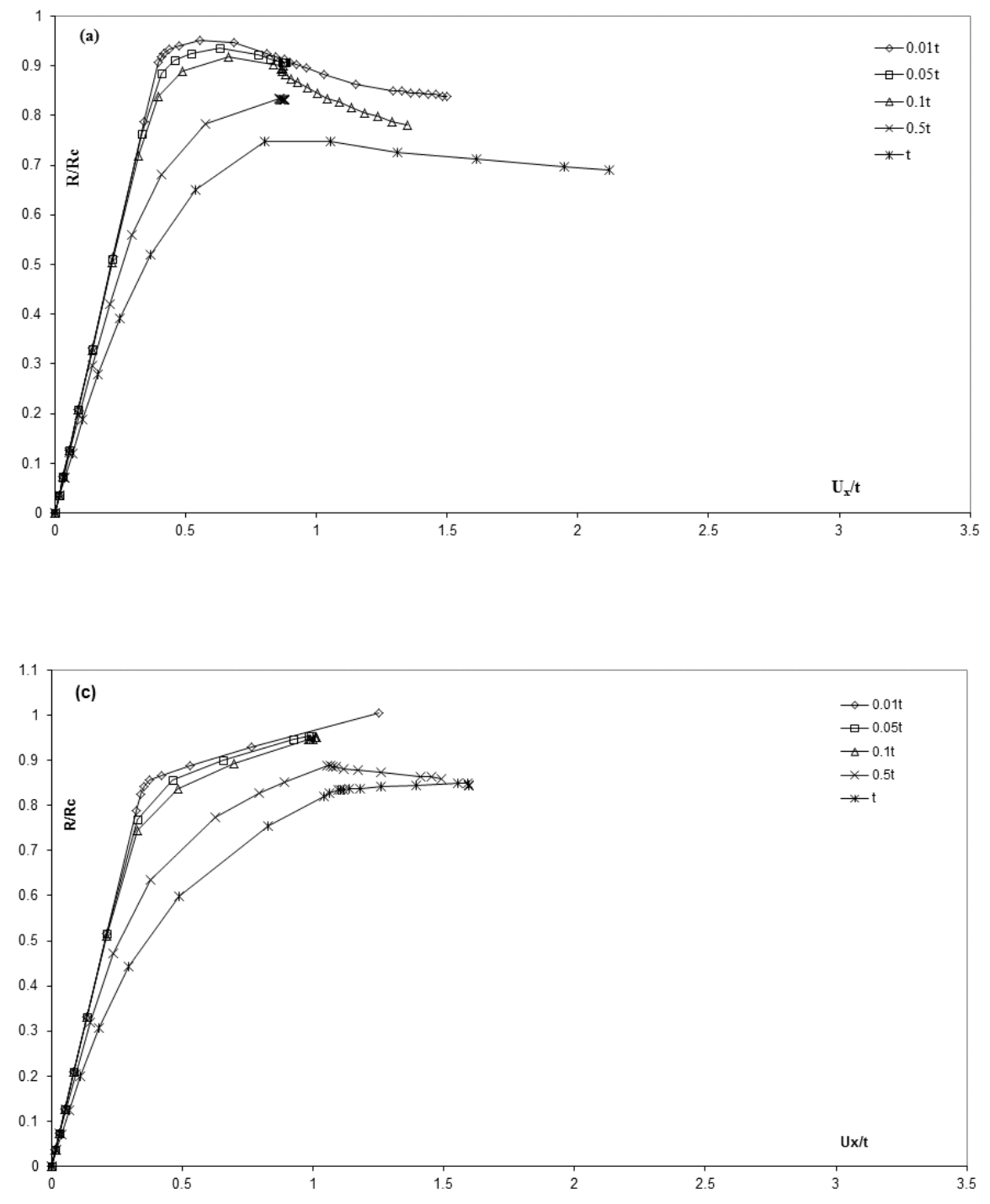

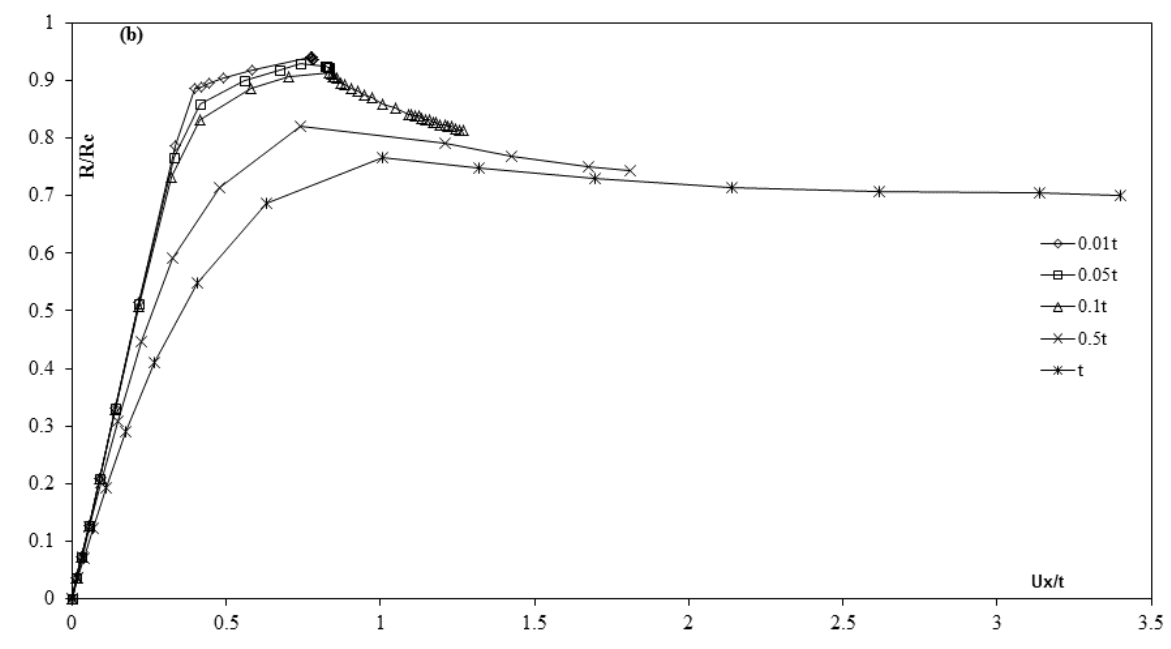

Fig. 14 Axial compressive load vs end shortening of a graphite epoxy cylindrical shell for different initial imperfection amplitudes, with a preloading of a) $\mathrm{T}=0.1 \mathrm{~T}_{c}$ b) $\left.\mathrm{T}=0.2 \mathrm{~T}_{c} \quad \mathrm{c}\right) \mathrm{T}=0.4 \mathrm{~T}_{\mathrm{c}}$ $\mathrm{L} / \mathrm{r}=5, \mathrm{r} / \mathrm{t}=30,[0 / 90 / 0]_{10 \mathrm{~T}}$ 


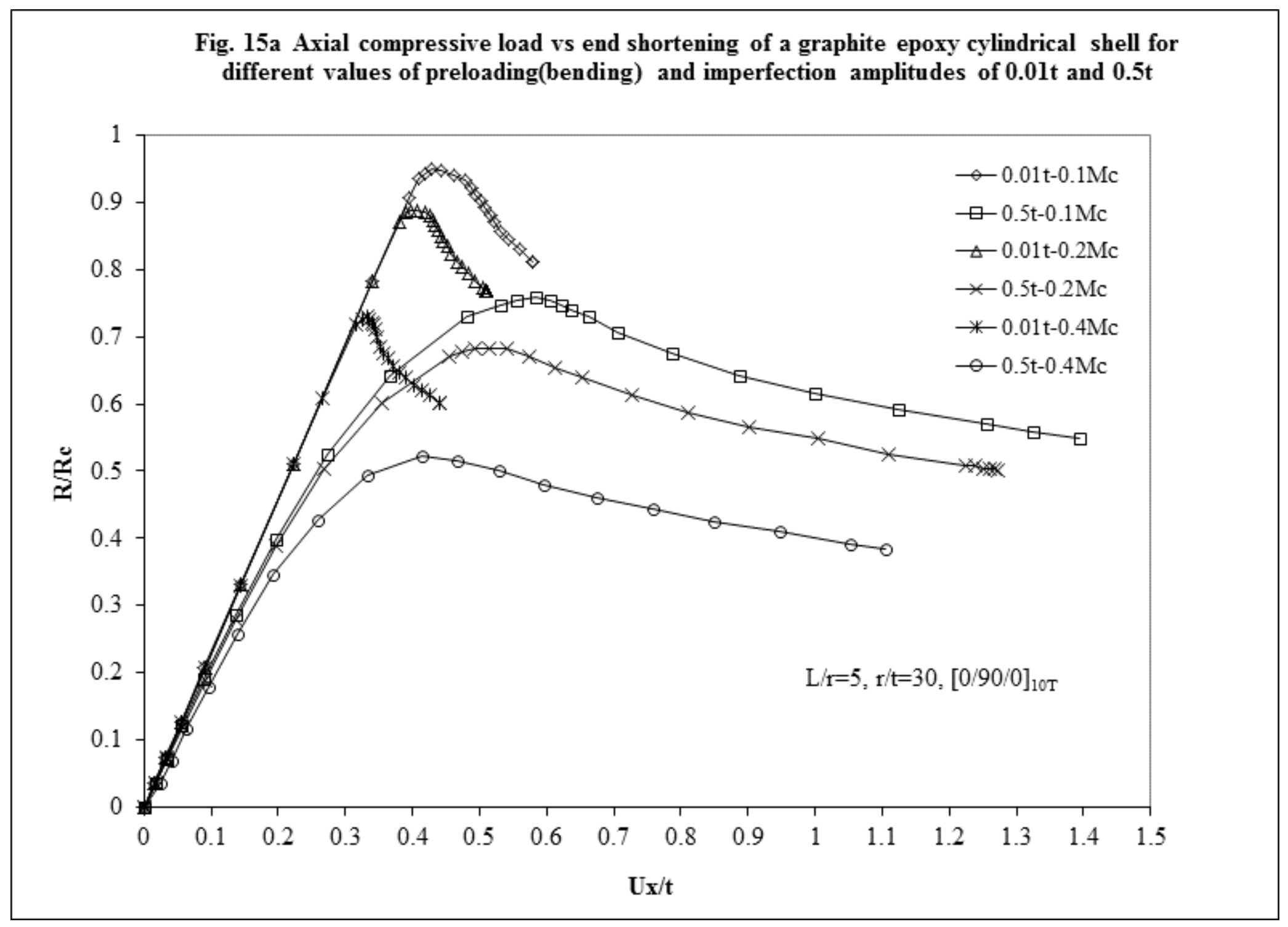




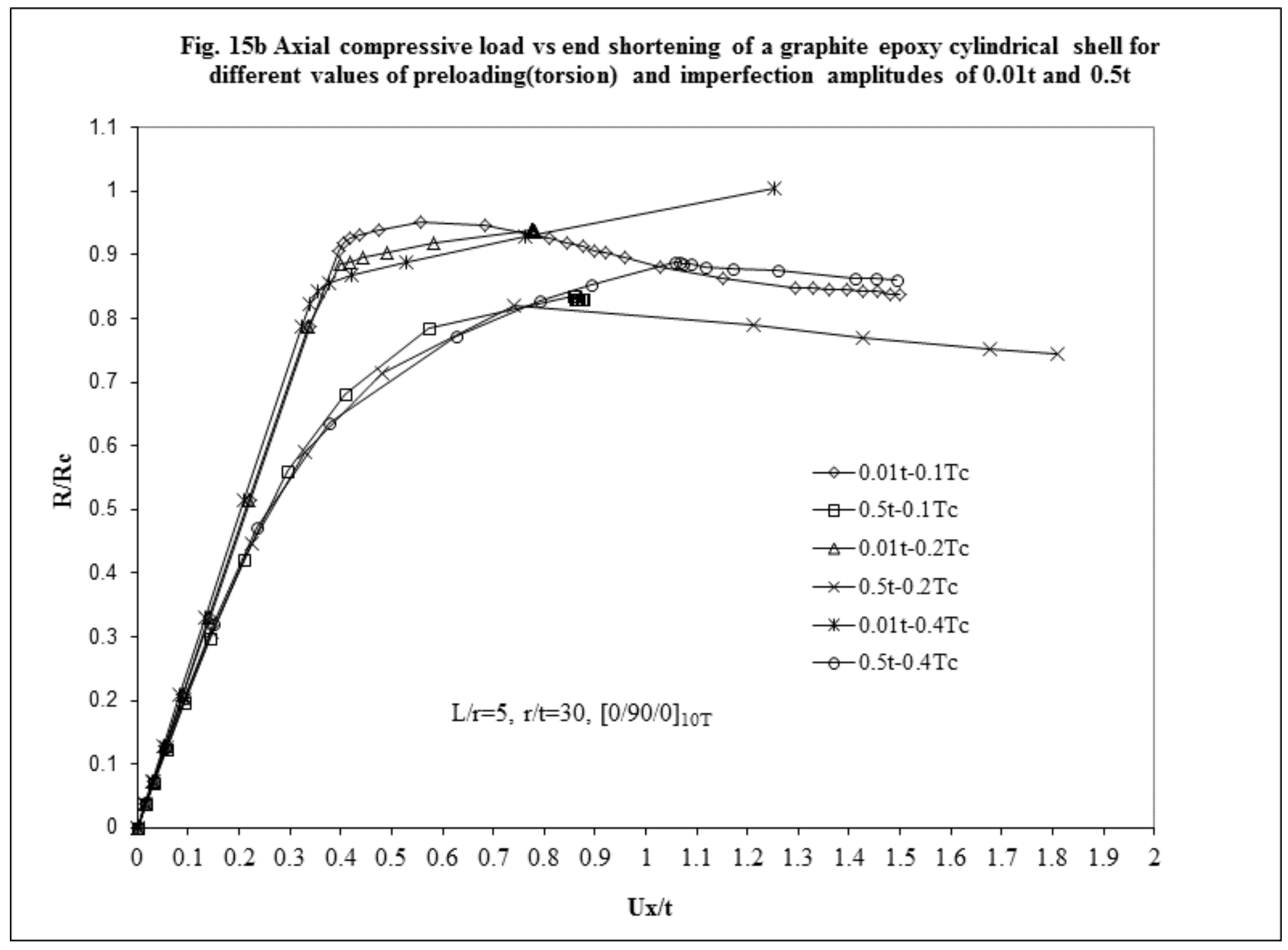




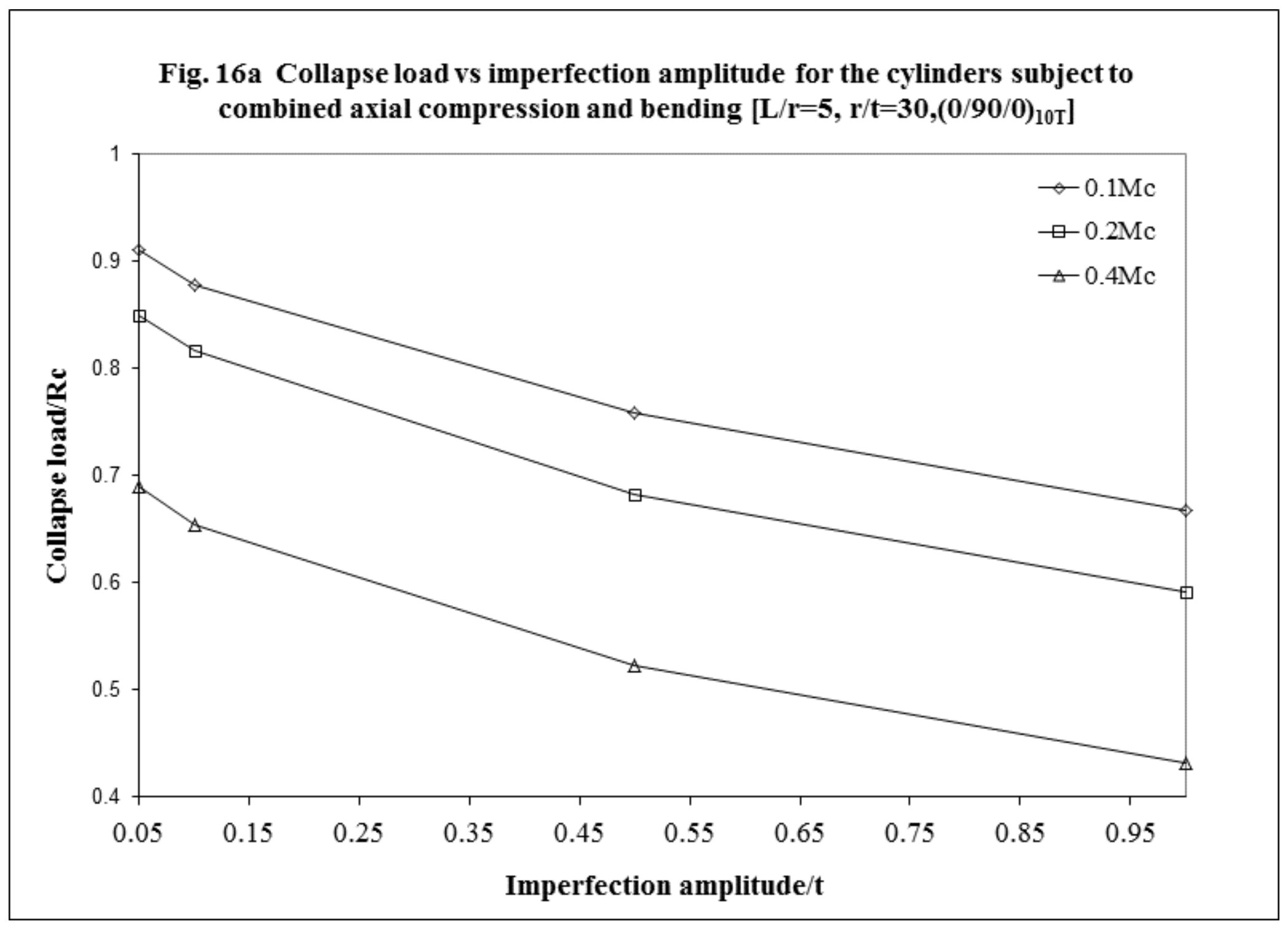




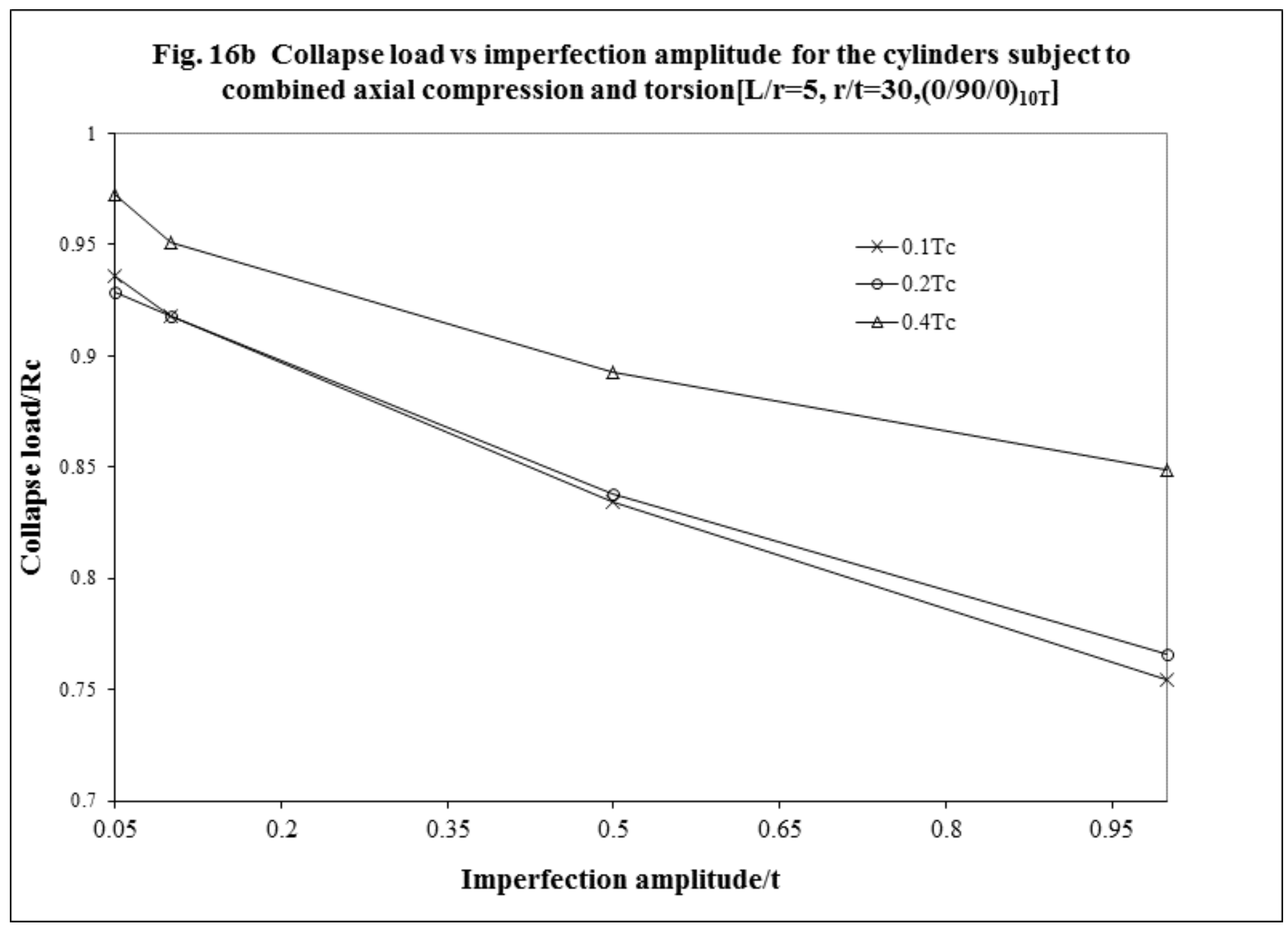


Table 1 Lamina engineering constants for the selected materials

\begin{tabular}{|l|c|c|c|c|c|}
\hline Material No. & $\mathrm{E}_{\mathrm{L}} / \mathrm{E}_{\mathrm{T}}$ & $v_{\mathrm{LT}}$ & $\mathrm{G}_{\mathrm{LT}} / \mathrm{E}_{\mathrm{T}}$ & $\mathrm{G}_{\mathrm{TT}} / \mathrm{G}_{\mathrm{LT}}$ & $\mathrm{E}_{\mathrm{T}}(\mathrm{GPa})$ \\
\hline Graphite-epoxy & 40 & 0.25 & 0.5 & 1.0 & 5.17 \\
\hline Kevlar-epoxy & 15.6 & 0.35 & 0.56 & 1.0 & 5.5 \\
\hline Boron-epoxy & 11.11 & 0.21 & 0.24 & 1.0 & 18.61 \\
\hline $\begin{array}{l}\text { Caron fibre } \\
\text { reinforced } \\
\text { polymer(CFRP) }\end{array}$ & 14.188 & 0.31946 & 0.654 & 1.0 & 8.7079 \\
\hline
\end{tabular}

